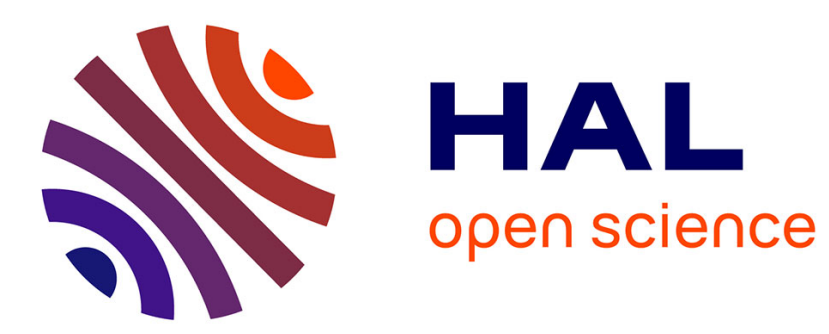

\title{
Effect of silver co-sputtering on V2O5 thin films for lithium microbatteries
}

Astrid Gies, Brigitte Pecquenard, Anas Benayad, Hervé Martinez, Danielle Gonbeau, H. Fuess, Alain Levasseur

\section{- To cite this version:}

Astrid Gies, Brigitte Pecquenard, Anas Benayad, Hervé Martinez, Danielle Gonbeau, et al.. Effect of silver co-sputtering on V2O5 thin films for lithium microbatteries. Thin Solid Films, 2008, 516 (21), pp.7271-7281. 10.1016/j.tsf.2007.12.165 . hal-00324189

\section{HAL Id: hal-00324189 \\ https://hal.science/hal-00324189}

Submitted on 24 Sep 2008

HAL is a multi-disciplinary open access archive for the deposit and dissemination of scientific research documents, whether they are published or not. The documents may come from teaching and research institutions in France or abroad, or from public or private research centers.
L'archive ouverte pluridisciplinaire HAL, est destinée au dépôt et à la diffusion de documents scientifiques de niveau recherche, publiés ou non, émanant des établissements d'enseignement et de recherche français ou étrangers, des laboratoires publics ou privés. 


\title{
Effect of silver co-sputtering on $\mathrm{V}_{2} \mathrm{O}_{5}$ thin films for lithium microbatteries
}

\author{
A. Gies, B. Pecquenard, A. Benayad, H. Martinez, D. Gonbeau, H. Fuess and A. Levasseur
}

\begin{abstract}
$\mathrm{Ag}_{y} \mathrm{~V}_{2} \mathrm{O}_{5}$-type thin films have been deposited by radiofrequency (rf) magnetron co-sputtering either in a pure argon or in a mixed argon/oxygen atmosphere with 14\% oxygen partial pressure using a metallic Ag target and a $\mathrm{V}_{2} \mathrm{O}_{5}$ target. The silver content in the thin films has been controlled by simply varying the rf power ratio applied to the two targets. We have investigated the influence of the dopant on the thin film composition, the structure and the morphology as well as on their electrochemical performances compared to undoped $\mathrm{V}_{2} \mathrm{O}_{5}$ thin films prepared in the same sputtering conditions. The thin films have been analyzed by various characterization methods such as Rutherford Backscattering Spectroscopy, X-ray Photoelectron Spectroscopy (XPS), Auger Electron Spectroscopy, X-ray diffraction, Scanning Electron Microscopy and electronic conductivity measurements. Electrochemical characterization has been carried out on two peculiar compositions: $\mathrm{Ag}_{0.32} \mathrm{~V}_{2} \mathrm{O}_{4.6}$ (obtained in absence of oxygen) and $\mathrm{Ag}_{0.26} \mathrm{~V}_{2} \mathrm{O}_{5}$ (prepared under $\mathrm{P}_{\mathrm{O} 2}=14 \%$ ). Furthermore, the redox processes occurring during lithium insertion and de-insertion have been investigated by using XPS. The $\mathrm{Ag}_{0.32} \mathrm{~V}_{2} \mathrm{O}_{4.6}$ thin film is amorphous and dense with a smooth surface and shows a good cycling stability as well as discharge capacity values similar to thus obtained for an amorphous $\mathrm{V}_{2} \mathrm{O}_{5}$ thin film prepared in absence of oxygen. The $\mathrm{Ag}_{0.26} \mathrm{~V}_{2} \mathrm{O}_{5}$ thin film is amorphous, porous and shows improved discharge capacities compared to crystallized $\mathrm{V}_{2} \mathrm{O}_{5}$ thin films, probably due to the additional participation of silver ions to the redox processes. Nevertheless, a continuous capacity fading is observed, as already mentioned for porous crystallized $\mathrm{V}_{2} \mathrm{O}_{5}$ thin films.
\end{abstract}

\section{Introduction}

During the last decade, the increasing use of miniaturized electronic devices has caused a strong demand for rechargeable electrochemical systems. Therefore, intensive research efforts are currently undertaken in developing and improving thin film microbatteries as possible integrated components in microelectronic devices [1] and [2]. These batteries can be fabricated in various shapes (recently even in $3 \mathrm{D}$ architectures [3] and [4]), different sizes and potentially on any type of substrate. Therefore, the possible applications for these batteries are numerous and mostly related to the smart card field, implantable medical devices and microelectromechanical systems. Even if thin film lithium microbatteries are about to be launched on the market, there is still a real challenge for enhancing the performances of the cathode material in order to satisfy the requirements of microelectronic systems.

Various transition metal sulfides and oxides such as TiS2 [5] and [6], LiCoO2 [1], [7] and [8] and LiMn2O4 [1] have already been studied as possible cathode material in thin film lithium microbatteries. Among the oxides, $\mathrm{V}_{2} \mathrm{O}_{5}$ seems to be a promising material due to its high energy density, the possibility to insert up to 3 lithium ions 
per $\mathrm{V}_{2} \mathrm{O}_{5}$ leading to a good capacity, the existence of various oxidation states for the vanadium [9] and the convenience to prepare it as a thin film. In a previous study, we have reported on the preparation and the characterization of undoped $\mathrm{V}_{2} \mathrm{O}_{5}$ thin films obtained by radiofrequency (rf) sputtering from a $\mathrm{V}_{2} \mathrm{O}_{5}$ target under various $\mathrm{Ar} / \mathrm{O}_{2}$ atmospheres and total gas pressures [10]. By tuning the deposition conditions and especially the oxygen partial pressure, we were able to prepare either amorphous and dense thin films with a smooth surface ( $\mathrm{pO} 2 \leq 10 \%$ ) or crystallized and porous thin films ( $\mathrm{pO} 2>10 \%$ ). The differences concerning the structure and the morphology can be mainly explained by a higher deposition rate for thin films prepared in absence of oxygen or at low oxygen partial pressure, that avoids an ordered arrangement of the sputtered particles arriving on the substrate. Best electrochemical discharge capacities have been obtained for crystallized thin films sputtered at a high total gas pressure. Nevertheless, for all crystallized thin films an important capacity fading is observed when cycled in the potential range [3.7-1.5 V]. In contrast, the amorphous and dense thin films show slightly lower discharge capacities but an excellent cycling stability when cycled in the same potential range. Moreover, they do not require any conventional annealing process necessarily used for LiMO2 thin films ( $\mathrm{M}=\mathrm{Ni}$, Co or $\mathrm{Mn}$ ), which imposes some limitations to the elaboration process of the complete all-solid-state microbattery.

Many studies have been carried out on bulk $\mathrm{V}_{2} \mathrm{O}_{5}$ doped by different elements such as $\mathrm{Ag}$ [11] and [12], $\mathrm{Fe}$ [13], $\mathrm{Cu}$ [14], [15] and [16] or $\mathrm{Cr}$ [17] in order to improve the discharge capacity and the long-term cycling stability. Despite the promising results obtained for these materials, only few studies have been achieved on doped $\mathrm{V}_{2} \mathrm{O}_{5}$ thin films [18], [19], [20] and [21]. In the case of silver-doped V2O5 thin films, only three different deposition methods have been used: dip-coating of xerogels [12], pulsed laser deposition [19] and [22] and co-sputtering [18]. Whatever the deposition technique, all researchers have mentioned an increase of the electronic conductivity due to the silver doping. The dip-coating method as well as the pulsed laser deposition has led to the composition range $\mathrm{Agy}_{2} \mathrm{O}_{5}$ with $0.1 \leq \mathrm{y} \leq 0.5$ [12], [19] and [22]. Except for $\mathrm{Ag}_{0.1} \mathrm{~V}_{2} \mathrm{O}_{5}$ prepared by dip-coating, all the thin films are amorphous. Best electrochemical performances in terms of capacity and cycling stability have been obtained for $\mathrm{Ag}_{0.5} \mathrm{~V}_{2} \mathrm{O}_{5}$. In the case of co-sputtered thin films, a very large composition range $(0.1 \leq \mathrm{y} \leq 1.8)$ has been reached by varying the power ratio applied to the two metallic $\mathrm{Ag}$ and $\mathrm{V}$ targets. The as-deposited thin films are amorphous and the highest discharge capacities have been observed for $\mathrm{Ag}_{0.8} \mathrm{~V}_{2} \mathrm{O}_{5}$ [18] and [23] .

In the present study we report on the deposition and the characterization of $\mathrm{Agy}_{2} \mathrm{O}_{5}$ thin films obtained by cosputtering from a metallic silver target and a ceramic V2O5 target under different $\mathrm{Ar} / \mathrm{O}_{2}$ atmospheres. The cosputtering technique seems to be an attractive method for the deposition of doped thin films because it allows the preparation of a large composition range using only two targets and by simply varying the power ratio applied to the two targets. The aim of this work is to give an insight on how the deposition conditions and the doping content influence the thin film composition, the structure and the morphology as well as the electrochemical properties. Therefore, a set of complementary investigation methods has been used to characterize the deposited thin films. The chemical compositions have been determined using Rutherford Backscattering Spectroscopy (RBS), X-ray Photoelectron Spectroscopy (XPS) and Auger Electron Spectroscopy (AES). Scanning Electron Microscopy (SEM) has been used to study the surface morphology and cross sections of the thin films. A structural analysis has been carried out using X-ray diffraction (XRD). The electronic conductivity measurements have been carried out using a standard four probe configuration set-up. Finally, the electrochemical performances have been evaluated by galvanostatic cycling in liquid electrolyte. In addition, exsitu XPS analyses have been carried out after mechanical erosion at different steps of the discharge and charge during the 1 st and the 10th cycle in order to investigate the redox processes occurring during lithium insertion 
and de-insertion.

\section{Experimental part}

Agy $_{2} \mathrm{O}_{5}$ thin films were prepared by if magnetron co-sputtering in a turbo-pumped sputtering chamber (HEF TSD250-RF) using a metallic silver target (Goodfellow, 99.9\%) and a $\mathrm{V}_{2} \mathrm{O}_{5}$ target, both targets having a diameter of $50 \mathrm{~mm}$. The $\mathrm{V}_{2} \mathrm{O}_{5}$ target was prepared by cold pressing and sintering at $600^{\circ} \mathrm{C}$ under air from a $\mathrm{V} 2 \mathrm{O} 5$ powder (99.99\%) purchased from Aldrich. A schematic illustration of the co-sputtering system is shown on Fig. 1. Prior to each deposition, vacuum was applied into the chamber until the pressure was about 10- $4 \mathrm{~Pa}$. All thin films were deposited at room temperature with no intentional heating of the substrates, and a target to substrate distance equal to $8 \mathrm{~cm}$. A nominal if power equal to $50 \mathrm{~W}$ was applied to the $\mathrm{V} 2 \mathrm{O} 5$ target whereas the one applied to the silver target was respectively equal to $3 \mathrm{~W}, 4 \mathrm{~W}$ and $5 \mathrm{~W}$. Before deposition, a pre-sputtering has been achieved systematically for $1 \mathrm{~h}$ in order to clean the target surfaces. The films were deposited at $1 \mathrm{~Pa}$ total gas pressure under two different atmospheres: pure argon (99.999\%) or a mixture of argon and oxygen $(99.99 \%)$ with an oxygen partial pressure set to $14 \%$. Thin films have been deposited during various deposition times and on different substrates depending on the characterization method: carbon was used for RBS measurements, silicon for XRD, aluminum for SEM analysis and stainless steel for electrochemical testing (because we need a conductive substrate). Note that no influence of the substrate nature on the morphology or the structure has been detected. In order to avoid any surface contamination, the samples were handled after deposition in an argon filled glove box and transferred to the different analysis systems via appropriate air tight containers.

Rutherford Backscattering Spectroscopy (RBS) was used to determine the thin film composition. The measurements were carried out at a backscattering angle of $165^{\circ}$ using an incident beam of $4 \mathrm{He}+$ ions with an energy of $2 \mathrm{Mev}$. The spectra were analyzed using the RUMP software [24].

X-ray Photoelectron Spectroscopy (XPS) analyses were carried out with a Surface Science Instruments spectrometer (model 301) using a focused and monochromatized Al Ka radiation (1486.6 eV). The calibration was done using the photoemission lines of $\mathrm{Au}(\mathrm{Au} 4 \mathrm{f7} / 2=83.9 \mathrm{eV}$, with reference to the Fermi level) and $\mathrm{Cu}$ (Cu2p3/2 = 932.5 eV). The Au4f7/2 full width at half maximum was equal to $0.86 \mathrm{eV}$ in the recording conditions and peaks were recorded with a constant pass energy of $50 \mathrm{eV}$. The experimental curve was fitted with a combination of Gaussian $(80 \%)$ and Lorentzian $(20 \%)$ functions. XPS analyses were carried out after mechanical erosion under ultra high vacuum (using a blade) instead of the usually performed ionic bombardment in order to avoid any non-intentional reduction or other modifications induced by the latter, as it has already been observed in the case of oxide or oxysulfide thin films [25] and [26].

Auger electron spectroscopy (AES) was carried out with a VG MICROLAB 310F in order to analyze the thin film homogeneity over thickness. The operating voltage of the Auger electron was fixed at $10 \mathrm{kV}$ with an adsorbed current of $5 \mathrm{nA}$. The bombardment with argon ions was achieved at $4 \mathrm{kV}$ (with an accelerated current of $0.5 \mu \mathrm{A}$ ) on a sample tilted from $60^{\circ}$.

The thin film surface and cross section were investigated by Scanning Electron Microscopy (SEM) using a JEOL JSM 5200 microscope (operating voltage: $20 \mathrm{kV}$ ). In order to prevent any charging of the samples by the electron beam during observation, the films were coated with a thin film of gold.

The structural properties of the thin films deposited on silicon substrate were studied by X-ray diffraction (XRD) using a PHILIPS PW 1730 diffractometer in Bragg-Brentano geometry using CuKa radiation. 
Electronic conductivity measurements were carried out using a standard four probe configuration set-up with direct current.

An electrochemical characterization was carried out by galvanostatic cycling using $\mathrm{Agy}_{2} \mathrm{O}_{5}$ thin films deposited on stainless steel substrates and a thin metallic lithium foil respectively as the positive and the negative electrode, both being separated by a glass fiber separator soaked with a liquid electrolyte (1 M LiPF6 in ethylcarbonate/diethylcarbonate). The current density was fixed to $15 \mu \mathrm{A} / \mathrm{cm} 2(\approx \mathrm{C} / 5)$ and the potential window was [3.7-1.5 V/Li]. Due to the very low weight of the thin films (typically around $0.20 \mathrm{mg}$ ), the inserted lithium amount was not known accurately (approximative error: 10\%).

\section{Results and discussion}

\subsection{Chemical composition and oxidation states}

First of all, the chemical composition of the $\mathrm{AgyV}_{2} \mathrm{O}_{5}$ thin films was investigated by RBS and XPS measurements. As can be noticed from the results shown in Table 1, an oxygen excess is systematically observed by RBS for all films due to a certain amount of oxygen adsorbed at the surface of the carbon substrate. By fitting the RBS spectra, we were not able to clearly separate the two contributions (oxygen from the film and oxygen adsorbed at the surface of the substrate). Therefore the RBS measurements were used to determine the $\mathrm{Ag} / \mathrm{V}$ ratio, whereas the oxygen content was deduced from the oxidation states of the vanadium and silver ions determined by XPS by supposing a formal oxidation state equal to -2 for the oxygen (Table 1). Note that no evidence of a lower oxidation state has been evidenced for oxygen, in contrast with sulfur that has already been detected in titanium oxysulfide thin films with two different oxidation states - 2 and - 1 corresponding respectively to S2- and S22[6] M.H. Lindic, B. Pecquenard, P. Vinatier, A. Levasseur, H. Martinez, D. Gonbeau, P.E. Petit and G. Ouvrard, Thin Solid Films 484 (2005), p. 113.

Furthermore, even small variations of the if power applied to the silver target (while maintaining a constant if power applied to the $\mathrm{V}_{2} \mathrm{O}_{5}$ target) result in a drastic variation of the silver content in the thin films, as illustrated on RBS spectra (Fig. 2) for two thin films respectively prepared at $4 \mathrm{~W}$ and $5 \mathrm{~W}$ in a mixed $\mathrm{Ar} / \mathrm{O} 2$ atmosphere. This is obviously related to the different nature of the two targets. For the metallic silver target, a small increase of the applied if power induces a strong increase of the deposition rate due to the high sputter yield of the metallic target compared to a ceramic one. In order to have a better control on the silver content, thin films were also deposited by using a ceramic $\mathrm{Ag}_{2} \mathrm{O}$ target. However, due to the low decomposition temperature $\left(\sim 160^{\circ} \mathrm{C}\right)$ of this oxide, a decomposition of the target surface occurs during sputtering caused by a heating of the target under argon ions bombardment. Therefore, this target was not convenient for the deposition of our $\mathrm{Agy}_{2} \mathrm{O}_{5}$ thin films. In order to investigate the formal oxidation state for the vanadium and silver ions, XPS measurements were carried out on different as-deposited $\mathrm{Agy}_{2} \mathrm{O}_{5}$ thin films prepared in absence of oxygen or at $14 \%$ oxygen partial pressure with a rf power applied to the metallic silver target equal to $4 \mathrm{~W}$ or $5 \mathrm{~W}$. As a preliminary step, several reference compounds have been characterized: $\mathrm{V}_{2} \mathrm{O}_{5}, \mathrm{VO}_{2}, \mathrm{~V}_{2} \mathrm{O}_{3}$, metallic silver and $\mathrm{Ag}_{2} \mathrm{O}$. The binding energies for the different reference compounds are listed in Table 2. The XPS spectra of the V2p and Ag3d core peaks are shown in Fig. 3 and Fig. 4 and all data are reported in Table 3. The spectra of undoped $\mathrm{V}_{2} \mathrm{O}_{5}$-type thin films obtained respectively at $0 \%$ and $14 \%$ oxygen partial pressure are given for comparison.

For thin films deposited in absence of oxygen and whatever the if power applied to the metallic silver target, the $\mathrm{V} 2 \mathrm{p} 3 / 2$ core peak presents two components, as it has already been observed for undoped $\mathrm{V}_{2} \mathrm{O}_{5}$ thin films 
prepared in absence of oxygen [10] (Fig. 3a):

- the most important component named A (60\%), located at $517.4 \mathrm{eV}$, corresponds to vanadium ions in the formal oxidation state +5 ,

- the component named B (40\%) on the lower binding energy side at $516.3 \mathrm{eV}$ is attributed to vanadium ions in a formal oxidation state +4 .

This behavior can be explained by a slight reduction of the target surface under the argon ions bombardment during sputtering. As the thin films are deposited in absence of oxygen, the reduced vanadium species cannot be re-oxidized in the sputtering chamber. Concerning the Ag3d core peak, the binding energies for the Ag3d5/2 and Ag3d3/2 core peaks were found respectively at 368.4 and $374.4 \mathrm{eV}$, indicating that the silver ions are in a metallic state for all these thin films (Fig. 4a).

In the case of thin films deposited at PO2 $=14 \%$, the analysis of the $\mathrm{V} 2 \mathrm{p}$ core peak, for $\mathrm{V}_{2} \mathrm{O}_{5}$ thin film and for the Agy $_{2} \mathrm{O}_{5}$ prepared at $5 \mathrm{~W}$, has shown that the vanadium ions are in their highest oxidation state $\mathrm{V}^{5+}(\mathrm{Fig}$. $3 \mathrm{~b})$. In contrast, for $\mathrm{AgyV}_{2} \mathrm{O}_{5}$ thin films obtained at $4 \mathrm{~W}$, the $\mathrm{V} 2 \mathrm{p}$ core peak is characterized by the co-existence of the two components $A$ and $B$, indicating a slight reduction of the vanadium ions $\left(16 \% \mathrm{~V}^{4+}\right)$ (Fig. $\left.3 b\right)$. In both films, silver is present as oxidized $\mathrm{Ag}^{+}$ions (Fig. 4b).

AES analyses of the different $\mathrm{V}_{2} \mathrm{O}_{5}$ and $\mathrm{Agy}_{2} \mathrm{O}_{5}$ thin films have shown that the chemical composition is quite homogeneous over the whole layer thickness for most of them. Nevertheless, for the $\mathrm{Ag}_{1.18} \mathrm{~V}_{2} \mathrm{O}_{4.8}$ film prepared in absence of oxygen, a higher silver content has been observed at the thin film surface compared to the core.

\subsection{Structural properties}

Fig. 5 shows $X$-ray diffractograms obtained in the Bragg-Brentano geometry for $\mathrm{V}_{2} \mathrm{O}_{5}$ and $A g y \mathrm{~V}_{2} \mathrm{O}_{5}$ thin films prepared in absence of oxygen. As can be seen from the patterns, the $\mathrm{V}_{2} \mathrm{O}_{5}$ thin film as well as $\mathrm{Agy}_{2} \mathrm{O}_{5}$ thin films obtained at $3 \mathrm{~W}$ and $4 \mathrm{~W}$ do not show any sharp diffraction peak and are therefore amorphous or at least nanocrystallized. The thin film obtained at $5 \mathrm{~W}$ is mainly amorphous but exhibits in addition two diffraction peaks attributed to metallic silver (Fig. $5 d$ ). As this thin film contains a large amount of silver ( $y=1.18)$, some metallic clusters might have been formed.

The diffraction patterns obtained for $\mathrm{V}_{2} \mathrm{O}_{5}$ and $\mathrm{AgyV}_{2} \mathrm{O}_{5}$ thin films deposited at $14 \%$ oxygen partial pressure are shown in Fig. 6. The $\mathrm{V}_{2} \mathrm{O}_{5}$ thin film exhibits several broad diffraction peaks characteristic of the well-known orthorhombic structure [27]. A strong preferential orientation with the c-axis perpendicular to the substrate is observed. For all $\mathrm{Agy}_{2} \mathrm{O}_{5}$ thin films, an important loss of crystallinity is observed, whatever the applied rf power. The as-deposited thin films are weakly crystallized, only the (110) diffraction peak remains with a very low intensity. This means that the introduction of silver into the $\mathrm{V}_{2} \mathrm{O}_{5}$ thin films induces a strong disorder into the structure. Note that in both Fig. 5 and Fig. 6), a thin peak corresponding to silicon as well as a line at low angle characteristic of $\mathrm{SiO}_{2}$ are observed, these originate from the silicon substrate.

\subsection{Morphology}

Fig. 7 shows SEM images of $\mathrm{V}_{2} \mathrm{O}_{5}$ and $\mathrm{AgyV}_{2} \mathrm{O}_{5}$ thin films deposited in absence of oxygen. All the thin films are highly dense with a smooth surface (Fig. $7 a-d$ ). In addition, the $\mathrm{Ag}_{1.18} \mathrm{~V}_{2} \mathrm{O}_{4.8}$ thin film deposited at $5 \mathrm{~W}$ exhibits the presence of some aggregates with a size close to $0.4 \mu \mathrm{m}$ which are dispersed inhomogeneously on the surface (Fig. 7d). For this peculiar film, the AES depth profile has evidenced a significantly higher silver content at the 
thin film surface, and the presence of metallic silver has been detected by X-ray diffraction. Therefore we can conclude that the aggregates observed on the film consist of metallic silver particles.

Fig. 8 shows the SEM images of thin films deposited at $14 \%$ oxygen partial pressure. As we have previously reported on undoped $\mathrm{V}_{2} \mathrm{O}_{5}$ thin films, the oxygen partial pressure plays a decisive role on the film morphology [10]. When the oxygen partial pressure is increased from $0 \%$ to $14 \%$, the thin films are no longer dense with a smooth surface, but highly porous and constituted of numerous tangled rods (Fig. 8a). The porous morphology is maintained for all $\mathrm{Agy}_{2} \mathrm{O}_{5}$ thin films with more or less significant modifications of the morphology depending on the silver content. The film sputtered with the highest if power $(5 \mathrm{~W})$ shows a well-defined columnar growth (Fig. $8 d$ ), whereas the films deposited at lower rf power ( $3 \mathrm{~W}$ or $4 \mathrm{~W}$ ) seem to have an intermediate morphology between the two previous ones (Fig. $8 \mathrm{~b}$ and $\mathrm{c}$ ).

\subsection{Electronic conductivity measurements}

Fig. 9 shows the evolution of the electronic conductivity as a function of $1 / \mathrm{T}$ for different thin films. The electronic conductivity of the crystallized $\mathrm{V}_{2} \mathrm{O}_{5}$ thin film is similar to that observed for the bulk material $(6.10-4 \mathrm{~S}$ $\mathrm{cm}-1$ at room temperature) [28], whereas the one obtained for the amorphous $\mathrm{V}_{2} \mathrm{O}_{5}$ thin film is lower $(2.10-5 \mathrm{~S}$ cm- 1 at RT). The $\mathrm{Ag}_{0.26} \mathrm{~V}_{2} \mathrm{O}_{5}$ thin film (prepared at $14 \%$ oxygen partial pressure) shows an increased electronic conductivity (1.8.10- $3 \mathrm{~S} \mathrm{~cm}-1$ at RT) compared to the undoped crystallized thin film, whereas the one obtained for $\mathrm{Ag}_{0.32} \mathrm{~V}_{2} \mathrm{O}_{4.6}$ (deposited in absence of oxygen) is similar to that of the pure amorphous thin film. The electronic conductivities as well as the activation energies are reported in Table 4. The activation energy has been calculated from the Arrhenius equation $\sigma=\sigma 0 \exp (-\mathrm{Ea} / \mathrm{kT}$ ), where $\sigma$ is the electronic conductivity, $\mathrm{T}$ the temperature, $\mathrm{k}$ the Boltzmann constant and Ea the activation energy. Note, that for $\mathrm{Ag}_{0.26} \mathrm{~V}_{2} \mathrm{O}_{5}$, the activation energy is also the lowest $\left(0.14 \mathrm{eV}\right.$ instead of $0.20 \mathrm{eV}$ for crystallized $\left.\mathrm{V}_{2} \mathrm{O}_{5}\right)$.

\subsection{Electrochemical properties}

\subsubsection{Galvanostatic cycling}

In order to investigate the electrochemical properties, $\mathrm{AgyV}_{2} \mathrm{O}_{5}$ thin films deposited onto stainless steel substrates have been used as positive electrode in a lithium battery cell and their performances have been compared to thus of amorphous or crystallized $\mathrm{V}_{2} \mathrm{O}_{5}$ thin films. Here, we will focus on two peculiar compositions, both of them prepared with a power of $4 \mathrm{~W}$ :

- $\mathrm{Ag}_{0.32} \mathrm{~V}_{2} \mathrm{O}_{4.6}$ prepared in absence of oxygen and showing a dense morphology

- $\mathrm{Ag}_{0.26} \mathrm{~V}_{2} \mathrm{O}_{5}$ prepared at $14 \%$ oxygen partial pressure and having a porous morphology.

Fig. 10 displays the first two galvanostatic cycles obtained for an amorphous $\mathrm{V}_{2} \mathrm{O}_{4.6}$ and $\mathrm{Ag}_{0.32} \mathrm{~V}_{2} \mathrm{O}_{4.6}$ thin films, both being prepared in absence of oxygen. These two materials show discharge and charge curves typical for an amorphous material. For the first cycle, a higher amount of lithium can be inserted into $\mathrm{Ag}_{0.32} \mathrm{~V}_{2} \mathrm{O}_{4.6}$ thin film compared the undoped one, therefore leading to a higher initial discharge capacity. Nevertheless, the reversibility of the insertion process is less efficient than for the undoped thin film and a higher amount of lithium remains irreversibly trapped in the thin film at the end of the first charge $\left(41 \%\right.$ for $\mathrm{Ag}_{0.32} \mathrm{~V}_{2} \mathrm{O}_{4.6}$ instead of $32 \%$ for $\left.\mathrm{V}_{2} \mathrm{O}_{4.6}\right)$. After 10 cycles, similar discharge capacities are obtained for both materials (Fig. 11), and a good cycling stability is observed confirming the strong influence of the morphology on the cycling stability; a dense morphology always leading to a good cycling stability [10] A. Gies, B. Pecquenard, A. Benayad, H. Martinez, D. Gonbeau, H. 
Fuess and A. Levasseur, Solid State lonics 176 (2005), p. 1627.

On Fig. 12 are represented the two first galvanostatic cycles for a crystallized $\mathrm{V}_{2} \mathrm{O}_{5}$ thin film and $\mathrm{Ag}_{0.26} \mathrm{~V}_{2} \mathrm{O}_{5}$ both deposited at $14 \%$ oxygen partial pressure. The $\mathrm{V}_{2} \mathrm{O}_{5}$ thin film shows a stepwise discharge curve with four plateaus respectively at 3.4, 3.2, 2.3 and $1.9 \mathrm{~V}$ as it has been previously observed for $\mathrm{V}_{2} \mathrm{O}_{5}$ bulk material and ascribed to the structural modifications ( $\alpha \rightarrow \varepsilon, \varepsilon \rightarrow \delta, \delta \rightarrow \gamma, \gamma \rightarrow \omega$ ) occurring during lithium insertion into the material [29], [30] and [31]. During the following charge and discharge curves, the plateaus are no more present and the charge/discharge profile approaches that of $\omega$ - $\mathrm{LixV}_{2} \mathrm{O}_{5}$ [30]. Concerning the $\mathrm{Ag}_{0.26} \mathrm{~V}_{2} \mathrm{O}_{5}$ thin film, the discharge curve shows three pseudo-plateaus at approximately 3.2, 2.5 and 1.8 V. As already mentioned for the thin film prepared in absence of oxygen, a higher amount of lithium can be inserted into $\mathrm{Ag}_{0.26} \mathrm{~V}_{2} \mathrm{O}_{5}$ compared to crystallized $\mathrm{V}_{2} \mathrm{O}_{5}$, thus leading to a higher discharge capacity for the doped thin film (Fig. 11). However, a higher amount of lithium remains irreversibly trapped in the doped material at the end of the first charge $(21 \%$ for $\mathrm{AgO}_{26} \mathrm{~V}_{2} \mathrm{O}_{5}$ instead of $16 \%$ for $\mathrm{V}_{2} \mathrm{O}_{5}$ ). Nevertheless, for the following cycles, a higher discharge capacity is maintained for $\mathrm{Ag}_{0.26} \mathrm{~V}_{2} \mathrm{O}_{5}$. The improvement is close to $25 \%$ after 30 cycles (Fig. 11). However, the cycling stability is not improved by the presence of silver in the thin film. In a previous study on $\mathrm{V}_{2} \mathrm{O}_{5}$ thin films, all films showing a dense morphology with a smooth surface exhibited excellent cycling stability, whereas the porous films showed higher initial discharge capacities but a poor capacity retention [10]. The electrochemical performances of the $\mathrm{AgyV}_{2} \mathrm{O}_{5}$ thin films investigated in this study are in good agreement with the previous results confirming the important role plays by the morphology on the electrochemical performances.

\subsubsection{XPS measurements during cycling}

In order to have a better insight on the influence of the silver doping on the redox processes occurring during cycling, ex-situ XPS measurements of V2p and Ag3d core peaks have been carried out after a mechanical erosion under ultra high vacuum. The analyses have been carried out at different stages of the 1st and the 10th cycle. Fig. 13 shows the XPS spectra of the $\mathrm{V} 2 p$ core peak obtained for $\mathrm{Ag}_{0.32} \mathrm{~V}_{2} \mathrm{O}_{4.6}$ (sputtered in absence of oxygen) and $\mathrm{Ag}_{0.26} \mathrm{~V}_{2} \mathrm{O}_{5}$ (prepared at $14 \%$ oxygen partial pressure). As already mentioned above, the asdeposited $\mathrm{Ag}_{0.32} \mathrm{~V}_{2} \mathrm{O}_{4.6}$ thin film is characterized by the presence of $60 \% \mathrm{~V} 5+$ and $40 \% \mathrm{~V}^{4+}$, whereas in the $\mathrm{Ag}_{0.26} \mathrm{~V}_{2} \mathrm{O}_{5}$ thin film $84 \% \mathrm{~V}^{5+}$ and $16 \% \mathrm{~V}^{4+}$ have been detected. For both materials, the redox processes are quite similar. During the discharge, a partial reduction of the $\mathrm{V}^{5+}$ ions into $\mathrm{V}^{4+}$ and further on $\mathrm{V}^{3+}$ takes place. Note that reference materials have been used to establish correlations between the oxidation state and the binding energy. In addition, this redox process is consistent with X-ray absorption spectroscopy analyses reported by Almeida onto $\mathrm{V}_{2} \mathrm{O}_{5}$ xerogel (see Ref. 14 in [32]). The $\mathrm{V}^{3+}$ ions are already present at a discharge potential of $3.2 \mathrm{~V}$ for $\mathrm{Ag}_{0.26} \mathrm{~V}_{2} \mathrm{O}_{5}$, whereas they appear at a lower potential (2.3 $\mathrm{V}$ ) for $\mathrm{Ag}_{0.32} \mathrm{~V}_{2} \mathrm{O}_{4.6}$. During the charge, the vanadium ions are re-oxidized. The redox processes are more reversible in the case of $\mathrm{Ag}_{0.32} \mathrm{~V}_{2} \mathrm{O}_{4.6}$, which is in good agreement with the good cycling stability of these thin films. Indeed, even after ten cycles, the proportions of $\mathrm{V}^{5+}$ and $\mathrm{V}^{4+}$ remain constant and approximately equal to $60 \%$ and $40 \%$. All XPS data obtained for the $\mathrm{V} 2 \mathrm{p}$ core peak are reported in Table 5. These results obtained on $\mathrm{AgyV}_{2} \mathrm{O}_{5}$ confirm a previous study achieved on $\mathrm{V}_{2} \mathrm{O}_{5}$ thin films [32] and [33], showing a good reversibility of the redox processes for the dense and amorphous thin film, whereas a degradation upon cycling has been noticed for the porous and crystallized films.

Fig. 14 represents the XPS spectra obtained for the Ag3d core peak. The corresponding binding energies are reported in Table 6. Regarding the $\mathrm{Ag}_{0.32} \mathrm{~V}_{2} \mathrm{O}_{4.6}$, the silver ions are in a metallic state and therefore do not participate to the redox processes occurring during cycling. On the contrary, in the case of $\mathrm{Ag}_{0.26} \mathrm{~V}_{2} \mathrm{O}_{5}$, the silver 
ions are in an oxidized state. During the discharge, they are reduced from $\mathrm{Ag}^{+}$to a metallic state and fully reoxidized during the charge, even after 10 cycles. Thus, both $\mathrm{Ag}$ and $\mathrm{V}$ are involved into the redox processes, leading to a higher discharge capacity for $\mathrm{Ag}_{0.26} \mathrm{~V}_{2} \mathrm{O}_{5}$ compared to crystallized $\mathrm{V}_{2} \mathrm{O}_{5}$ thin film.

\section{Conclusion}

In this study, the if magnetron co-sputtering technique was successfully used to prepare, under pure argon or mixed $\mathrm{Ar} / \mathrm{O}_{2}$ atmosphere, $\mathrm{AgyV}_{2} \mathrm{O}_{5}$ thin films with various compositions by using only two targets. Depending on the sputtering conditions, two types of thin films have been prepared:

- dense and amorphous thin films with a smooth surface for deposition in absence of oxygen

- porous and mostly amorphous thin films under $14 \%$ oxygen partial pressure, with a morphology depending on silver content.

Note that aggregates of metallic silver have been clearly evidenced on the thin film surface of a film containing a high amount of silver and deposited under pure argon.

The main objective of this work was to study the influence of the morphology and the doping content on the electrochemical performances. So, we have focused our electrochemical investigations on two $\mathrm{Agy}_{2} \mathrm{O}_{5}$ thin films leading to interesting results.

Best discharge capacities have been obtained for $\mathrm{Ag}_{0.26} \mathrm{~V}_{2} \mathrm{O}_{5}$ but a continuous capacity fading upon cycling has been observed. On the contrary, $\mathrm{Ag}_{0.32} \mathrm{~V}_{2} \mathrm{O}_{4.6}$ shows slightly lower discharge capacities but an excellent cycling stability, due to its dense morphology. This confirms the results obtained for $\mathrm{V}_{2} \mathrm{O}_{5}$ thin films, showing that a dense morphology with a smooth surface will always lead to a good cycling stability.

The good cycling stability observed for $\mathrm{Ag}_{0.32} \mathrm{~V}_{2} \mathrm{O}_{4.6}$ is mainly attributed to a good reversibility of the redox processes for vanadium, characterized by a partial reduction of $\mathrm{V}^{5+}$ ions into $\mathrm{V}^{4+}$ and further on $\mathrm{V}^{3+}$ during the discharge and their reoxidation during the charge, while silver remains in a metallic state and do not participate to the processes. The better discharge capacity, compared to crystallized $\mathrm{V}_{2} \mathrm{O}_{5}$, evidenced for $\mathrm{Ag}_{0.26} \mathrm{~V}_{2} \mathrm{O}_{5}$ is attributed to the additional participation to the redox processes of silver which exists in an oxidized state $\mathrm{Ag}^{+}$. Moreover, we have noticed an increase of the electronic conductivity for this composition compared to the crystallized $\mathrm{V}_{2} \mathrm{O}_{5}$ material.

\section{Acknowledgment}

The authors wish to thank the DFG (Deutsche Forschungsgemeinschaft) for financial support, Michel Lahaye (CECAMA) for AES measurements and Rodolph Decourt (ICMCB) for electronic conductivity measurements. 


\section{Figure captions}

Figure 1: Schematic illustration of the co-sputtering system used for the deposition of $\mathrm{Ag}_{\mathrm{y}} \mathrm{V}_{2} \mathrm{O}_{5}$ thin films.

Figure 2: RBS spectra for two $\mathrm{Ag}_{\mathrm{y}} \mathrm{V}_{2} \mathrm{O}_{5}$ thin films deposited at $14 \%$ oxygen partial pressure and with a) $4 \mathrm{~W}$ or b) $5 \mathrm{~W}$ rf power applied to the Ag target. The continuous line corresponds to the simulated spectra [24].

Figure 3: XPS V2p core peaks for $\mathrm{V}_{2} \mathrm{O}_{5}(0 \mathrm{~W})$ and $\mathrm{Ag}_{\mathrm{y}} \mathrm{V}_{2} \mathrm{O}_{5}$ thin films deposited at two different $\mathrm{rf}$ powers applied to the silver target (4 W and $5 \mathrm{~W})$ : a) in absence of oxygen, b) under $\mathrm{P}_{\mathrm{O}_{2}}=14 \%$.

Figure 4: XPS Ag3d core peaks for two $\mathrm{Ag}_{\mathrm{y}} \mathrm{V}_{2} \mathrm{O}_{5}$ thin films deposited at $4 \mathrm{~W}$ and $5 \mathrm{~W}$ (power applied to the Ag target): a) in absence of oxygen, b) under $\mathrm{P}_{\mathrm{O}_{2}}=14 \%$.

Figure 5: XRD diffraction patterns obtained for $\mathrm{V}_{2} \mathrm{O}_{5}$ (a) and different $\mathrm{Ag}_{\mathrm{y}} \mathrm{V}_{2} \mathrm{O}_{5}$ thin films deposited in absence of oxygen with the following rf powers applied to the $\mathrm{Ag}$ target $3 \mathrm{~W}(\mathrm{~b}), 4 \mathrm{~W}(\mathrm{c}), 5 \mathrm{~W}(\mathrm{~d})$.

Figure 6: XRD diffraction patterns obtained for different $\mathrm{Ag}_{\mathrm{y}} \mathrm{V}_{2} \mathrm{O}_{5}$ thin films deposited at $14 \%$ oxygen partial pressure with the following rf powers applied to the Ag target 5 $\mathrm{W}(\mathrm{a}), 4 \mathrm{~W}(\mathrm{~b}), 3 \mathrm{~W}(\mathrm{c})$ and for $\mathrm{V}_{2} \mathrm{O}_{5}(\mathrm{~d})$. 
Figure 7: SEM images for $\mathrm{V}_{2} \mathrm{O}_{5}$ (a) and different $\mathrm{Ag}_{\mathrm{y}} \mathrm{V}_{2} \mathrm{O}_{5}$ thin films deposited in absence of oxygen with the following rf powers applied to the Ag target $3 \mathrm{~W}$ (b), $4 \mathrm{~W}$ (c), $5 \mathrm{~W}(\mathrm{~d})$.

Figure 8: SEM images for $\mathrm{V}_{2} \mathrm{O}_{5}$ (a) and different $\mathrm{Ag}_{\mathrm{y}} \mathrm{V}_{2} \mathrm{O}_{5}$ thin films deposited at $14 \%$ oxygen partial pressure with the following rf powers applied to the Ag target $3 \mathrm{~W}$ (b), 4 $\mathrm{W}(\mathrm{c}), 5 \mathrm{~W}(\mathrm{~d})$.

Figure 9: Evolution of the electronic conductivity as a function of 1/T for amorphous and crystallized $\mathrm{V}_{2} \mathrm{O}_{5}$ thin films and two $\mathrm{Ag}_{\mathrm{y}} \mathrm{V}_{2} \mathrm{O}_{5}$ thin films: $\mathrm{Ag}_{0.32} \mathrm{~V}_{2} \mathrm{O}_{4.6}$ (prepared in absence of oxygen) and $\mathrm{Ag}_{0.26} \mathrm{~V}_{2} \mathrm{O}_{5}$ (deposited at $14 \%$ oxygen partial pressure).

Figure 10: First two galvanostatic cycles for $\mathrm{V}_{2} \mathrm{O}_{4.6}$ and $\mathrm{Ag}_{0.32} \mathrm{~V}_{2} \mathrm{O}_{4.6}$ thin films. Both materials have been deposited in absence of oxygen.

Figure 11: Capacity evolution as a function of the cycle number for undoped and Agdoped $\mathrm{V}_{2} \mathrm{O}_{5}$ thin films prepared in absence of oxygen $(\square, \square)$ or at $14 \%$ oxygen partial pressure $(\boldsymbol{\Delta}, \Delta)$.

Figure 12: First two galvanostatic cycles for $\mathrm{V}_{2} \mathrm{O}_{5}$ and $\mathrm{Ag}_{0.26} \mathrm{~V}_{2} \mathrm{O}_{5}$ thin films. Both materials have been deposited at $14 \%$ oxygen partial pressure.

Figure 13: Evolution of the V2p core peak upon cycling for $\mathrm{Ag}_{0.32} \mathrm{~V}_{2} \mathrm{O}_{4.6}\left(\mathrm{P}_{\mathrm{O}_{2}}=0 \%\right)$ and $\mathrm{Ag}_{0.26} \mathrm{~V}_{2} \mathrm{O}_{5}\left(\mathrm{P}_{\mathrm{O}_{2}}=14 \%\right)$. 
Figure 14: Evolution of the Ag3d core peak upon cycling for $\mathrm{Ag}_{0.26} \mathrm{~V}_{2} \mathrm{O}_{5}\left(\mathrm{P}_{\mathrm{O}_{2}}=14 \%\right)$. 


\section{Table captions}

Table 1: Chemical compositions determined by RBS and XPS measurements for $\mathrm{Ag}_{\mathrm{y}} \mathrm{V}_{2} \mathrm{O}_{5}$ thin films obtained for different rf powers applied to the silver target, in absence of oxygen or at $14 \%$ oxygen partial pressure.

Table 2: XPS V2 $\mathrm{p}_{3 / 2}$ and $\mathrm{Ag} 3 \mathrm{~d}_{5 / 2}$ binding energies (eV) as well as the full width at half maximum obtained for different reference compounds (in parentheses).

Table 3: XPS V2 $\mathrm{p}_{3 / 2}$ and $\mathrm{Ag} 3 \mathrm{~d}_{5 / 2}$ core peak binding energies (eV) for pure $\mathrm{V}_{2} \mathrm{O}_{5}$ and $\mathrm{Ag}_{\mathrm{y}} \mathrm{V}_{2} \mathrm{O}_{5}$ thin films prepared in absence of oxygen or at $14 \%$ oxygen partial pressure. The relative percentages of the different oxidation states as well as the full width at half maximum are indicated.

Table 4: Activation energies and electronic conductivities at room temperature for amorphous $\mathrm{V}_{2} \mathrm{O}_{4.6}$, crystallized $\mathrm{V}_{2} \mathrm{O}_{5}$ and two $\mathrm{Ag}_{\mathrm{y}} \mathrm{V}_{2} \mathrm{O}_{5}$ thin films.

Table 5: XPS V2 $\mathrm{p}_{3 / 2}$ binding energies (eV) at different steps (D: discharge, C: charge) of the $1^{\text {st }}$ and the $10^{\text {th }}$ galvanostatic cycle for $\mathrm{Ag}_{0.32} \mathrm{~V}_{2} \mathrm{O}_{4.6}$ (sputtered in absence of oxygen) and $\mathrm{Ag}_{0.26} \mathrm{~V}_{2} \mathrm{O}_{5}$ (prepared at $14 \%$ oxygen partial pressure). The relative percentages of the different oxidation states as well as the full width at half maximum are indicated. 
Table 6: XPS Ag3d binding energies (eV) at different steps (D: discharge, C: charge) of the $1^{\text {st }}$ and the $10^{\text {th }}$ cycle for $\mathrm{Ag}_{0.26} \mathrm{~V}_{2} \mathrm{O}_{5}$ (deposited at $14 \%$ oxygen partial pressure). 


\begin{tabular}{|c|c|c|c|c|}
\hline $\begin{array}{l}\text { Oxygen partial } \\
\text { pressure [\%] }\end{array}$ & $\begin{array}{l}\text { Power silver } \\
\text { target }[\mathbf{W}]\end{array}$ & $\begin{array}{c}\text { Chemical comp } \\
\text { RBS }\end{array}$ & $\begin{array}{l}\text { n determined by } \\
\text { XPS }\end{array}$ & \\
\hline \multirow{4}{*}{0} & 0 & $\mathrm{~V}_{2} \mathrm{O}_{4.8}$ & $\mathrm{~V}_{2} \mathrm{O}_{4.6}$ & \\
\hline & 3 & $\mathrm{Ag}_{0.07} \mathrm{~V}_{2} \mathrm{O}_{5.4}$ & ------ & \\
\hline & 4 & $\mathrm{Ag}_{0.32} \mathrm{~V}_{2} \mathrm{O}_{5.6}$ & $\mathrm{Ag}_{0.32} \mathrm{~V}_{2} \mathrm{O}_{4.6}$ & \\
\hline & 5 & $\mathrm{Ag}_{1.18} \mathrm{~V}_{2} \mathrm{O}_{5.7}$ & $\mathrm{Ag}_{1.18} \mathrm{~V}_{2} \mathrm{O}_{4.8}$ & \\
\hline \multirow{5}{*}{14} & 0 & $\mathrm{~V}_{2} \mathrm{O}_{5.7}$ & $\mathrm{~V}_{2} \mathrm{O}_{5}$ & \\
\hline & 3 & $\mathrm{Ag}_{0.19} \mathrm{~V}_{2} \mathrm{O}_{5.4}$ & ------ & \\
\hline & 4 & $\mathrm{Ag}_{0.26} \mathrm{~V}_{2} \mathrm{O}_{5.4}$ & $\mathrm{Ag}_{0.26} \mathrm{~V}_{2} \mathrm{O}_{5}$ & \\
\hline & 5 & $\mathrm{Ag}_{1.16} \mathrm{~V}_{2} \mathrm{O}_{5.7}$ & $\mathrm{Ag}_{1.16} \mathrm{~V}_{2} \mathrm{O}_{5.6}$ & \\
\hline & & Table 1 & & Deleted: $\mathrm{T}$ \\
\hline
\end{tabular}




\begin{tabular}{|c|c|c|c|c|c|c|}
\hline $\begin{array}{l}\text { reference } \\
\text { compound }\end{array}$ & $\mathrm{v}^{5+} 2 \mathrm{p}_{3 / 2}(\mathrm{eV})$ & $v^{4+} 2 p_{3 / 2}(e V)$ & $\mathrm{V}^{3+} 2 \mathrm{p}_{3 / 2}(\mathrm{eV})$ & $\mathrm{Ag}^{0} 3 d_{5 / 2}(\mathrm{eV})$ & $\mathrm{Ag}^{+} 3 \mathrm{~d}_{5 / 2}(\mathrm{eV})$ & \\
\hline $\mathrm{V}_{2} \mathrm{O}_{5}$ & $\begin{array}{c}517.4 \\
(1.2)\end{array}$ & ----- & ----- & ------ & ------ & \\
\hline $\mathrm{VO}_{2}$ & ------ & $\begin{array}{r}516.2 \\
(1.8)\end{array}$ & ------ & ------ & ------ & \\
\hline $\mathrm{V}_{2} \mathrm{O}_{3}$ & ----- & ----- & $\begin{array}{l}515.0 \\
(1.8)\end{array}$ & --- & ----- & \\
\hline metallic Ag & ----- & ----- & ------ & $\begin{array}{l}368.6 \\
(0.9)\end{array}$ & ----- & \\
\hline $\mathrm{Ag}_{2} \mathrm{O}$ & ------ & ----- & ------ & ------ & $\begin{array}{r}368.0 \\
(1.0)\end{array}$ & \\
\hline & & & $\overline{l e} 2$ & & & $\begin{array}{l}\text { Deleted: } \uparrow \\
\text { ף Page Break }\end{array}$ \\
\hline
\end{tabular}




\begin{tabular}{|c|c|c|c|c|c|}
\hline $\begin{array}{c}\text { Oxygen partial } \\
\text { pressure [\%] }\end{array}$ & $\begin{array}{l}\text { Power Ag } \\
\text { target [W] }\end{array}$ & $\mathrm{v}^{5+} 2 \mathrm{p}_{3 / 2}(\mathrm{eV})$ & $\mathrm{V}^{4+} 2 \mathrm{p}_{3 / 2}(\mathrm{eV})$ & $\mathrm{Ag}^{0} 3 d_{5 / 2}(\mathrm{eV})$ & $\mathrm{Ag}^{+} 3 \mathrm{~d}_{5 / 2}(\mathrm{eV})$ \\
\hline & 0 & $\begin{array}{c}517.4-(1.4) \\
60 \%\end{array}$ & $\begin{array}{c}516.4-(1.4) \\
40 \%\end{array}$ & ------ & ----- \\
\hline \multirow[t]{3}{*}{0} & 4 & $\begin{array}{c}517.4-(1.6) \\
60 \%\end{array}$ & $\begin{array}{c}516.3-(1.6) \\
40 \%\end{array}$ & $\begin{array}{c}368.4-(1.5) \\
100 \%\end{array}$ & ----- \\
\hline & 5 & $\begin{array}{c}517.4-(1.6) \\
80 \%\end{array}$ & $\begin{array}{c}516.4-(1.6) \\
20 \%\end{array}$ & $\begin{array}{c}368.5-(1.3) \\
100 \%\end{array}$ & ----- \\
\hline & 0 & $\begin{array}{c}517.4-(1.2) \\
100 \%\end{array}$ & ------ & ------ & ------ \\
\hline \multirow[t]{2}{*}{14} & 4 & $\begin{array}{c}517.4-(1.2) \\
84 \%\end{array}$ & $\begin{array}{c}516.2-(1.2) \\
16 \%\end{array}$ & ------ & $\begin{array}{c}367.9-(1.3) \\
100 \%\end{array}$ \\
\hline & 5 & $\begin{array}{c}517.7-(1.4) \\
100 \%\end{array}$ & ------ & ------ & $\begin{array}{c}368.1-(1.3) \\
100 \%\end{array}$ \\
\hline
\end{tabular}

Table 3 


\begin{tabular}{ccc}
\hline Composition & Ea (eV) & $\sigma\left(\Omega^{-1} \mathrm{~cm}^{-1}\right)$ at $25^{\circ} \mathrm{C}$ \\
\hline $\mathrm{V}_{2} \mathrm{O}_{4.6}$ amorphous & 0.21 & $0.24 .10^{-4}$ \\
\hline $\mathrm{V}_{2} \mathrm{O}_{5}$ crystallized & 0.20 & $6.1 .10^{-4}$ \\
\hline $\mathrm{Ag}_{0.32} \mathrm{~V}_{2} \mathrm{O}_{4.6}$ & 0.22 & $0.17 .10^{-4}$ \\
\hline $\mathrm{Ag}_{0.26} \mathrm{~V}_{2} \mathrm{O}_{5}$ & 0.14 & $18.10^{-4}$ \\
\hline
\end{tabular}

Table 4 


\begin{tabular}{|c|c|c|c|c|}
\hline $\begin{array}{l}\text { thin film } \\
\text { composition }\end{array}$ & $\begin{array}{c}\text { Cycle and } \\
\text { potential (V/ Li) }\end{array}$ & $V^{5+} 2 p_{3 / 2}(e V)$ & $v^{4+} 2 p_{3 / 2}(e V)$ & $\mathrm{V}^{3+} 2 \mathrm{p}_{3 / 2}(\mathrm{eV})$ \\
\hline \multirow{6}{*}{$\mathrm{Ag}_{0.32} \mathrm{~V}_{\mathbf{2}} \mathrm{O}_{4.8}$} & as-deposited & $\begin{array}{c}517.4-(1.6) \\
60 \%\end{array}$ & $\begin{array}{c}516.3-(1.6) \\
40 \%\end{array}$ & ----- \\
\hline & $1^{\text {st }}$ D 2.3 & $\begin{array}{c}517.4-(1.7) \\
63 \%\end{array}$ & $\begin{array}{c}516.3-(1.7) \\
37 \%\end{array}$ & ------ \\
\hline & $1^{\text {st }} \mathrm{D} 1.5$ & $\begin{array}{c}517.4-(1.7) \\
30 \%\end{array}$ & $\begin{array}{c}516.2-(1.7) \\
42 \%\end{array}$ & $\begin{array}{c}515.0-(1.7) \\
28 \%\end{array}$ \\
\hline & $1^{\text {st }}$ C 3.7 & $\begin{array}{c}517.4-(1.7) \\
65 \%\end{array}$ & $\begin{array}{c}516.3-(1.4) \\
35 \%\end{array}$ & ------ \\
\hline & $10^{\text {th }} \mathrm{D} 1.5$ & $\begin{array}{c}517.4-(1.6) \\
28 \%\end{array}$ & $\begin{array}{c}516.1-(1.6) \\
48 \%\end{array}$ & $\begin{array}{c}514.9-(1.6) \\
24 \%\end{array}$ \\
\hline & $10^{\text {th }} C 3.7$ & $\begin{array}{c}517.4-(1.7) \\
63 \%\end{array}$ & $\begin{array}{c}516.2-(1.7) \\
37 \%\end{array}$ & ------ \\
\hline \multirow{6}{*}{$\mathrm{Ag}_{0.26} \mathrm{~V}_{2} \mathrm{O}_{5}$} & as-deposited & $\begin{array}{c}517.4-(1.2) \\
84 \%\end{array}$ & $\begin{array}{c}516.2-(1.2) \\
16 \%\end{array}$ & ----- \\
\hline & $1^{\text {st }}$ D 2.3 & $\begin{array}{c}517.4-(1.4) \\
34 \%\end{array}$ & $\begin{array}{c}516.4-(1.4) \\
47 \%\end{array}$ & $\begin{array}{c}515.5-(1.4) \\
19 \%\end{array}$ \\
\hline & $1^{\text {st }} \mathrm{D} 1.5$ & $\begin{array}{c}517.4-(1.7) \\
23 \%\end{array}$ & $\begin{array}{c}516.3-(1.7) \\
47 \%\end{array}$ & $\begin{array}{c}515.3-(1.7) \\
30 \%\end{array}$ \\
\hline & $1^{\text {st }} C 3.7$ & $\begin{array}{c}517.4-(1.4) \\
73 \%\end{array}$ & $\begin{array}{c}516.3-(1.4) \\
27 \%\end{array}$ & ------ \\
\hline & $10^{\text {th }} \mathrm{D} 1.5$ & $\begin{array}{c}517.4-(1.7) \\
22 \%\end{array}$ & $\begin{array}{c}516.3-(1.7) \\
40 \%\end{array}$ & $\begin{array}{c}515.0-(1.7) \\
38 \%\end{array}$ \\
\hline & $10^{\text {th }} C 3.7$ & $\begin{array}{c}517.4-(1.6) \\
64 \%\end{array}$ & $\begin{array}{c}516.3-(1.6) \\
36 \%\end{array}$ & ------ \\
\hline
\end{tabular}

Table 5 


\begin{tabular}{|c|c|c|c|}
\hline $\begin{array}{l}\text { Thin film } \\
\text { composition }\end{array}$ & $\begin{array}{l}\text { Cycle and } \\
\text { potential } \\
\text { (V/Li) }\end{array}$ & $\mathrm{Ag}^{0} 3 \mathrm{~d}_{5 / 2}(\mathrm{eV})$ & $\mathrm{Ag}^{+} 3 \mathrm{~d}_{5 / 2}(\mathrm{eV})$ \\
\hline \multirow{6}{*}{$\mathrm{Ag}_{0.26} \mathrm{~V}_{2} \mathrm{O}_{5}$} & as-deposited & ------- & $\begin{array}{c}367.9-(1.3) \\
100 \%\end{array}$ \\
\hline & $1^{\text {st }} \mathrm{D} 2.3$ & $\begin{array}{c}368.8-(1.1) \\
13 \%\end{array}$ & $\begin{array}{c}368.0-(1.1) \\
87 \%\end{array}$ \\
\hline & $1^{\text {st }} \mathrm{D} 1.5$ & $\begin{array}{c}368.8-(1.1) \\
15 \%\end{array}$ & $\begin{array}{c}367.8-(1.1) \\
85 \%\end{array}$ \\
\hline & $1^{\text {st }} \mathrm{C} 3.7$ & ----- & $\begin{array}{c}367.8-(1.4) \\
100 \%\end{array}$ \\
\hline & $10^{\text {th }} \mathrm{D} 1.5$ & $\begin{array}{c}368.8-(1.1) \\
13 \%\end{array}$ & $\begin{array}{c}367.8-(1.1) \\
87 \%\end{array}$ \\
\hline & $10^{\text {th }} C 3.7$ & ----- & $\begin{array}{c}368.1-(1.3) \\
100 \%\end{array}$ \\
\hline
\end{tabular}

Table 6 


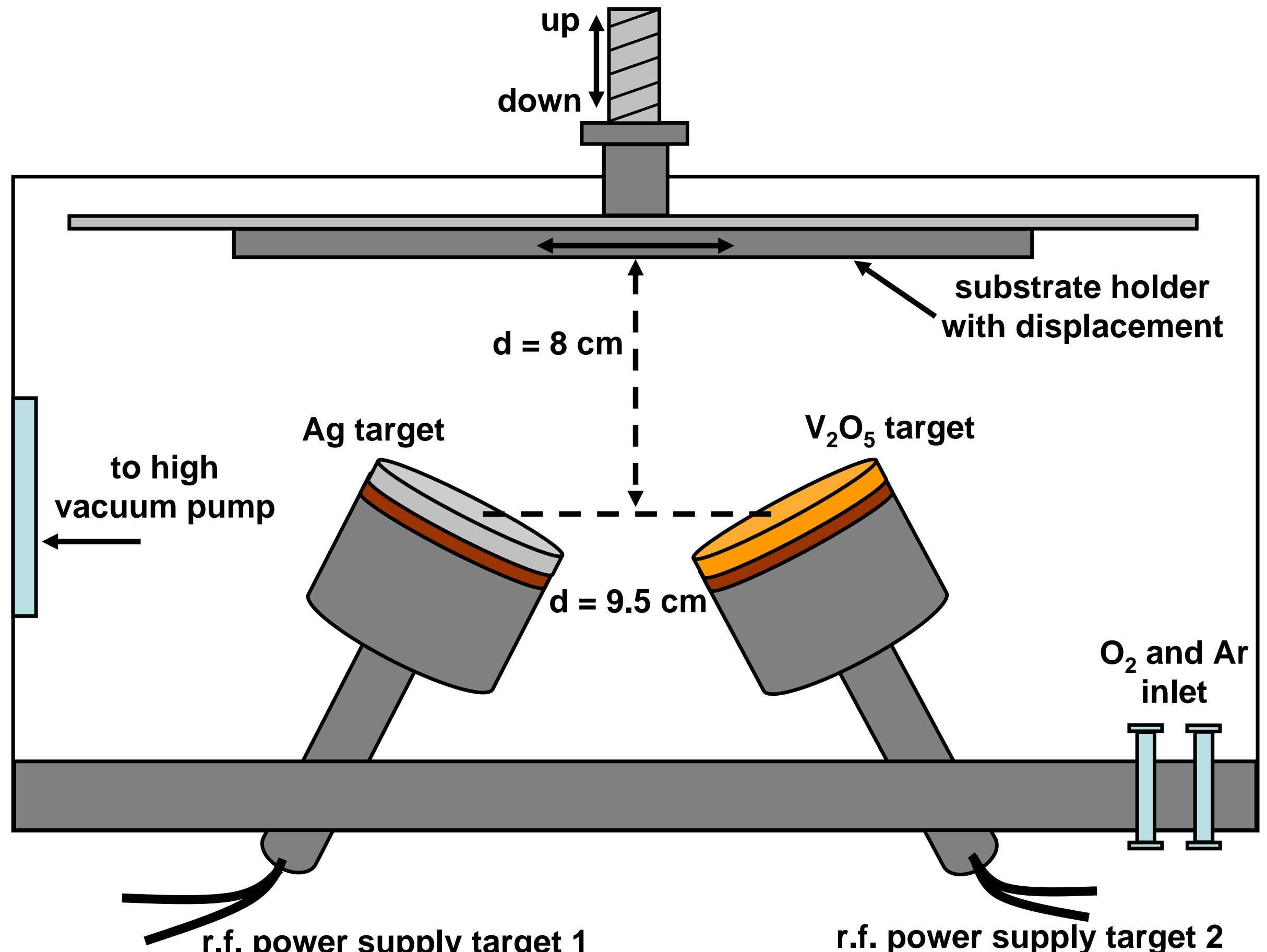

r.f. power supply target 1

r.f. power supply target 2 

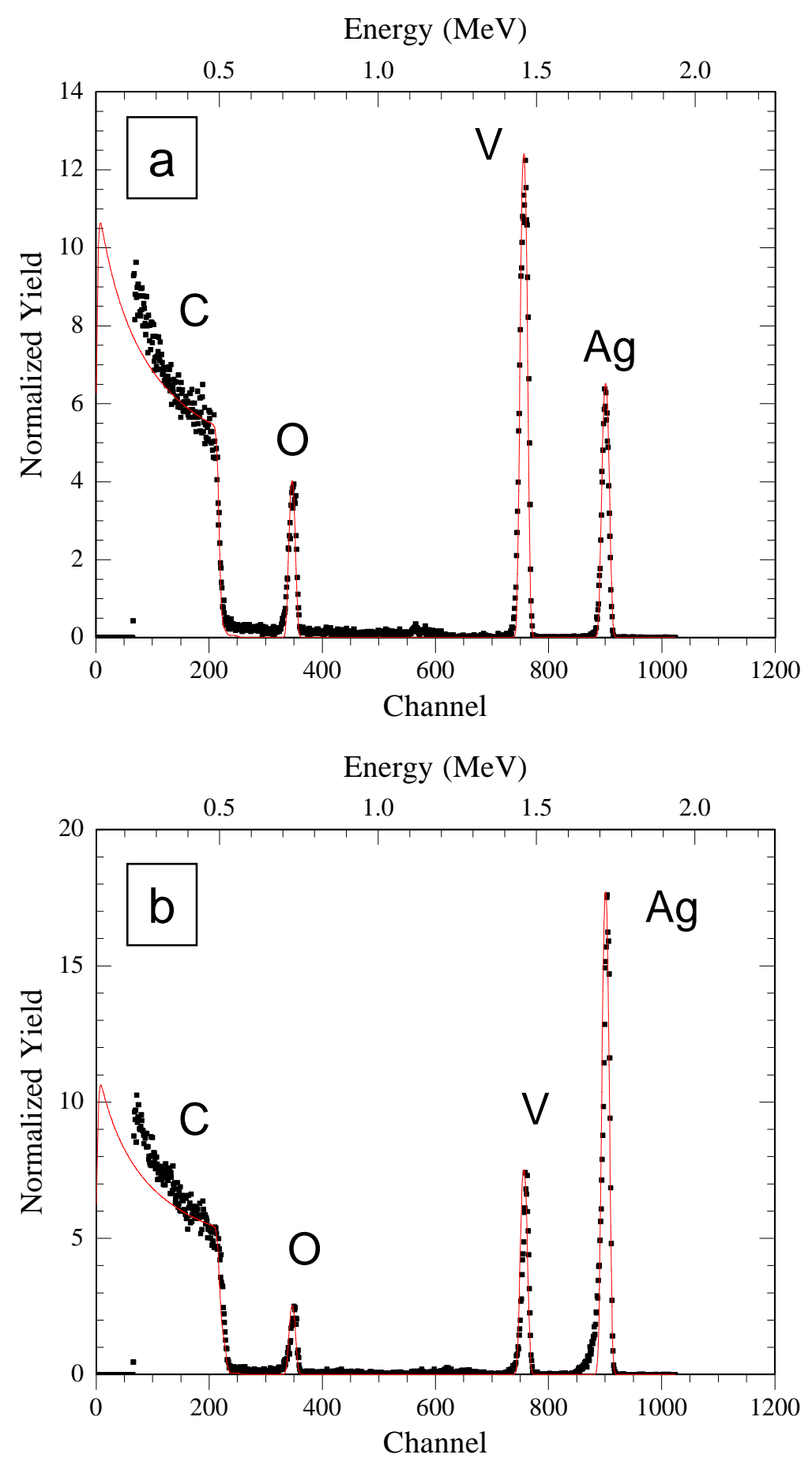

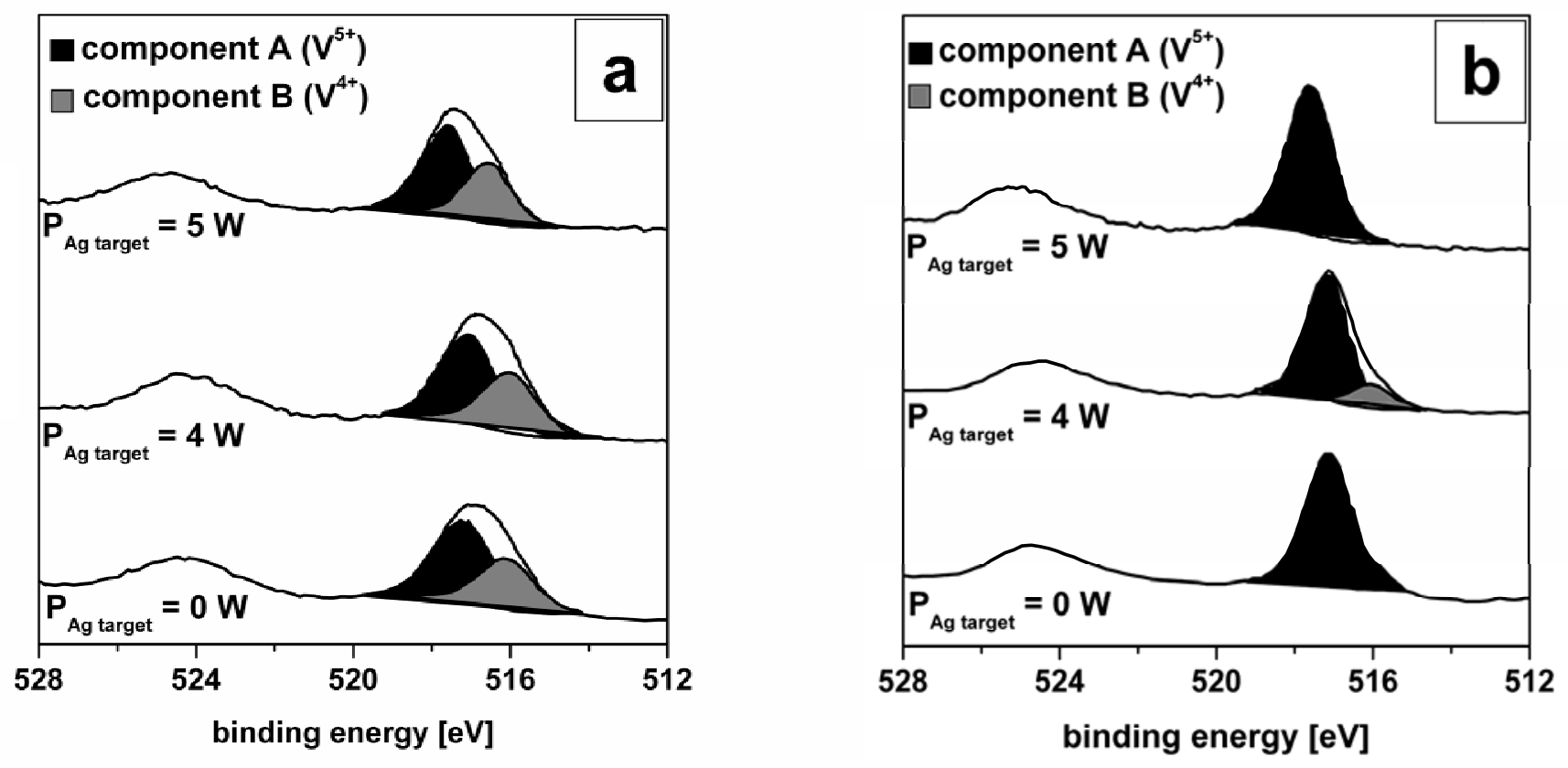

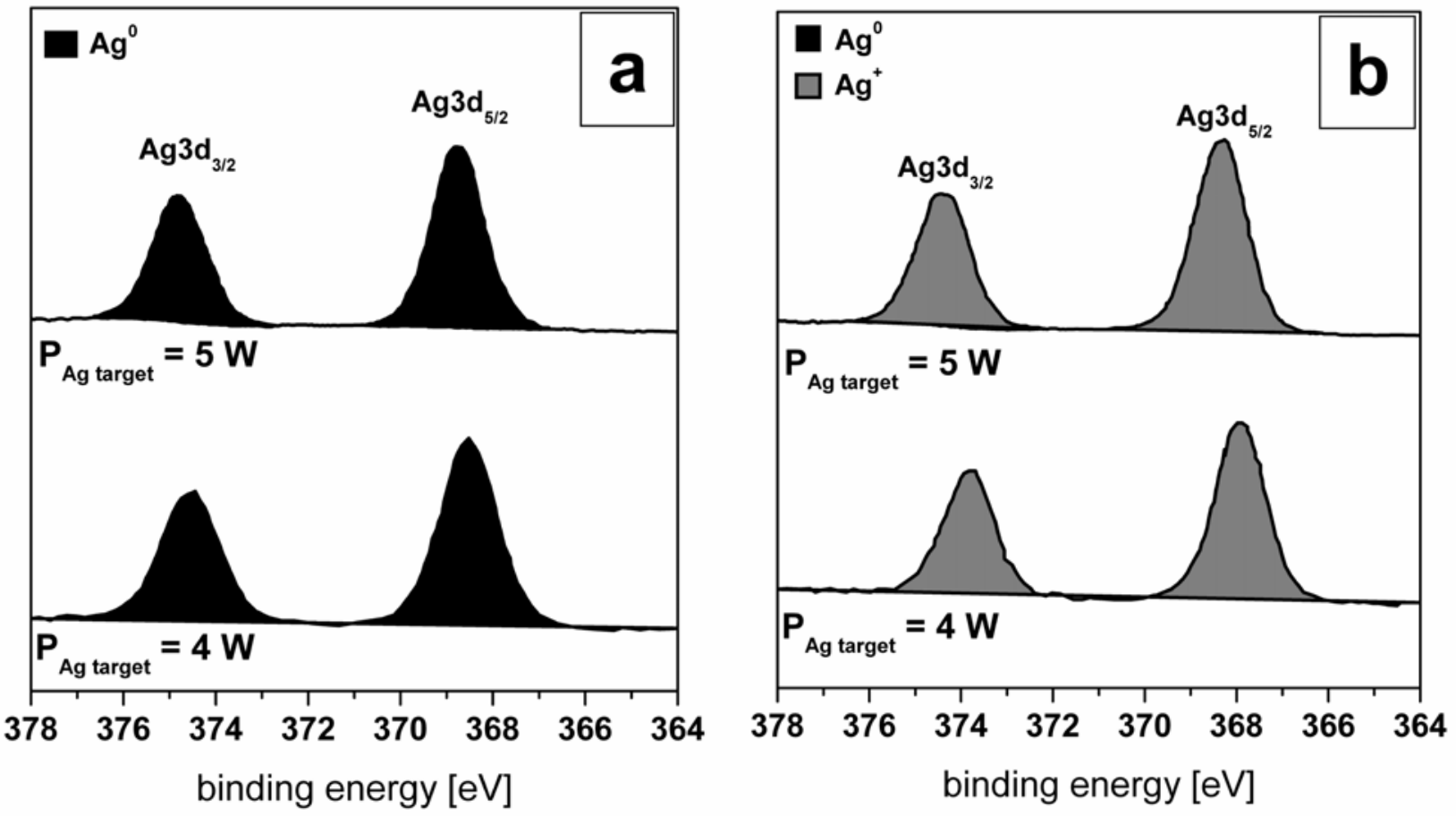

binding energy [eV]

binding energy $[\mathrm{eV}]$ 


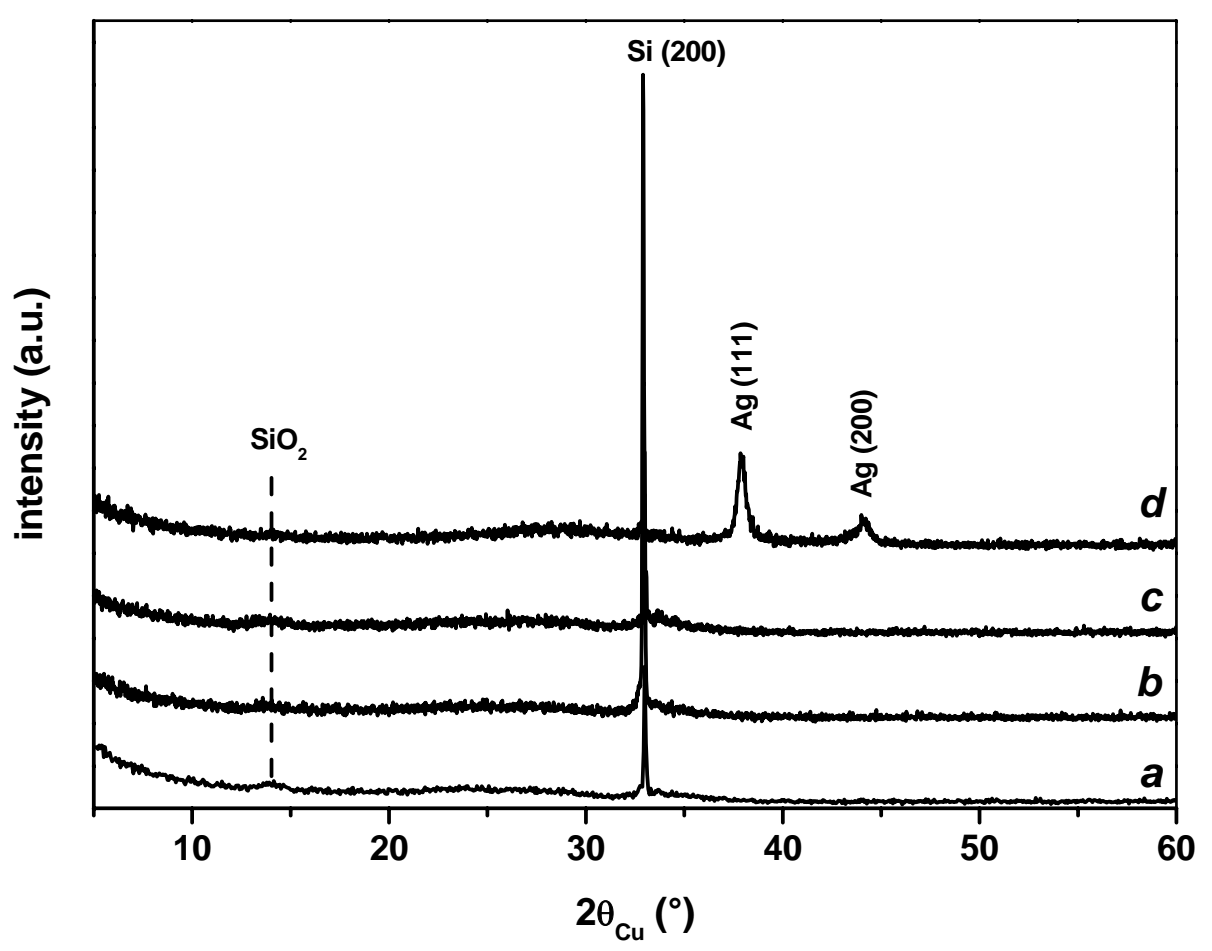

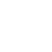




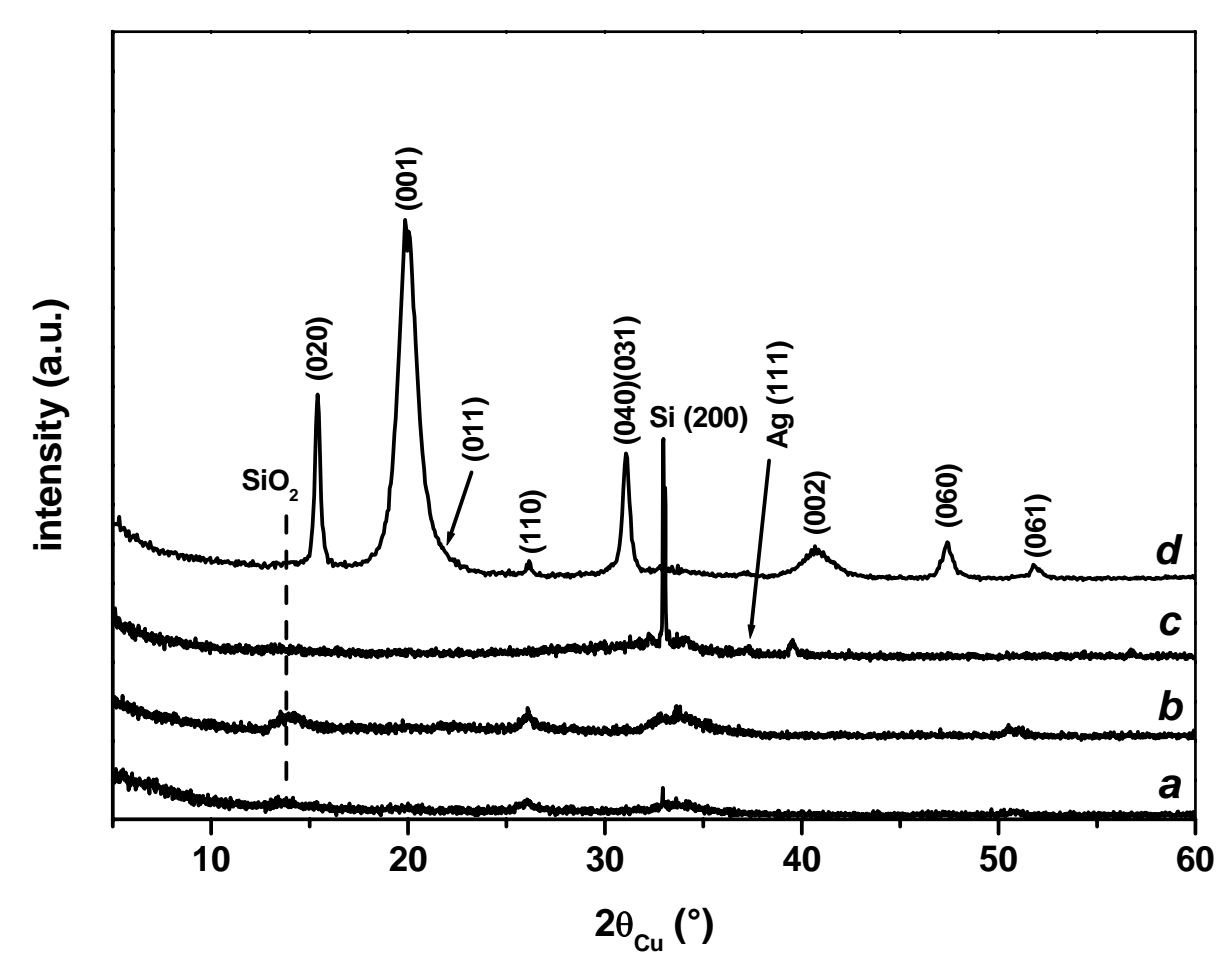


Figure

Click here to download high resolution image
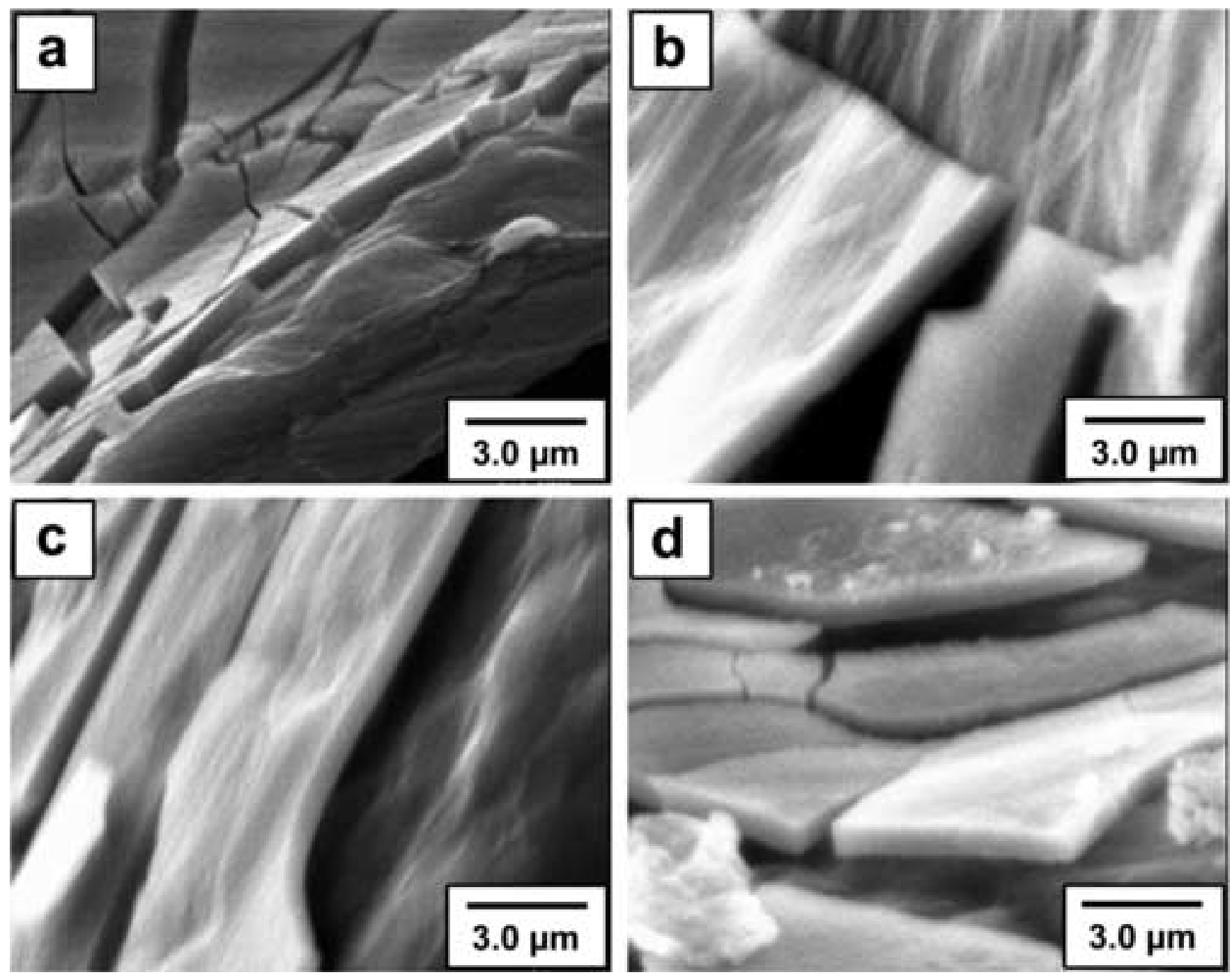
Figure

Click here to download high resolution image
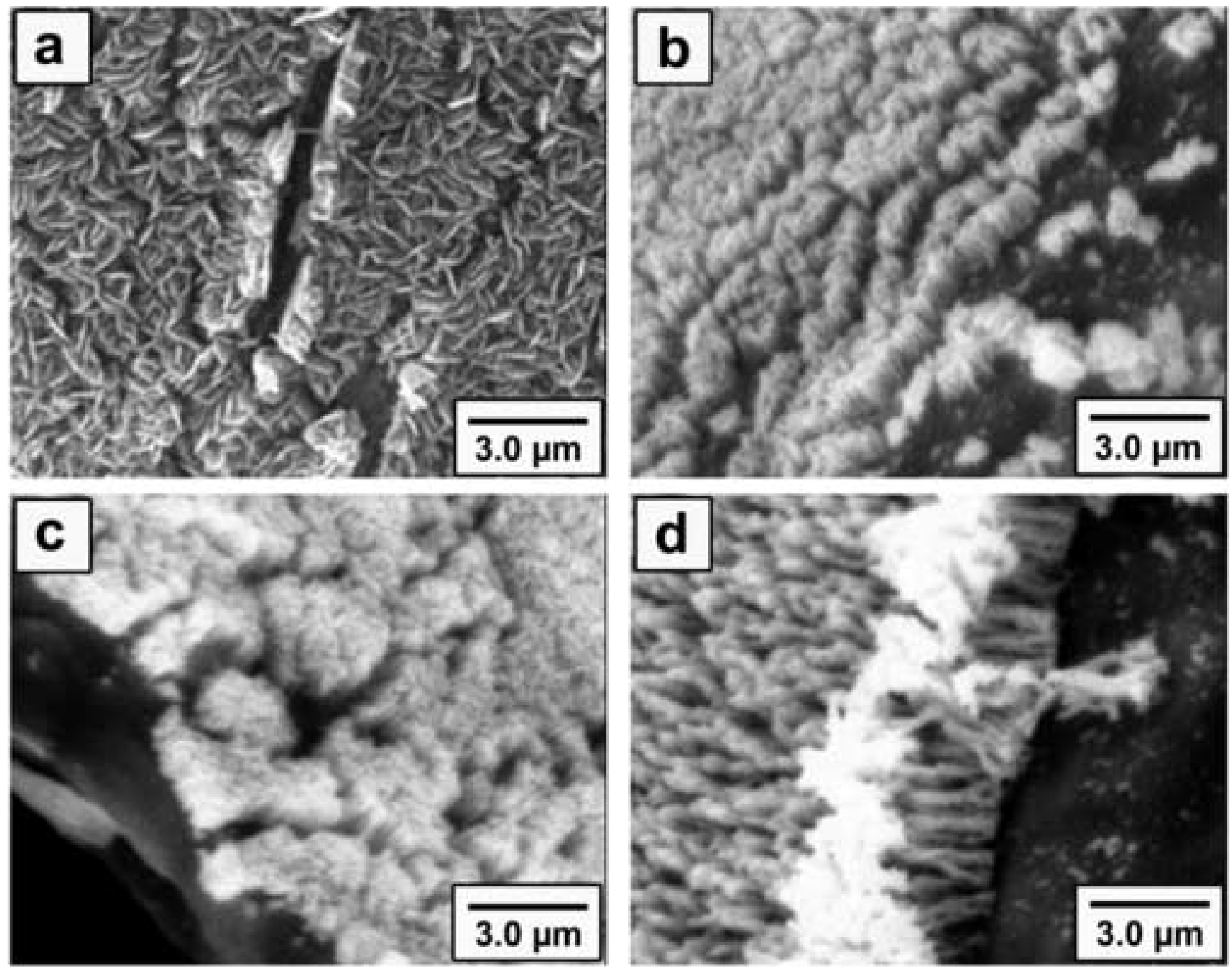


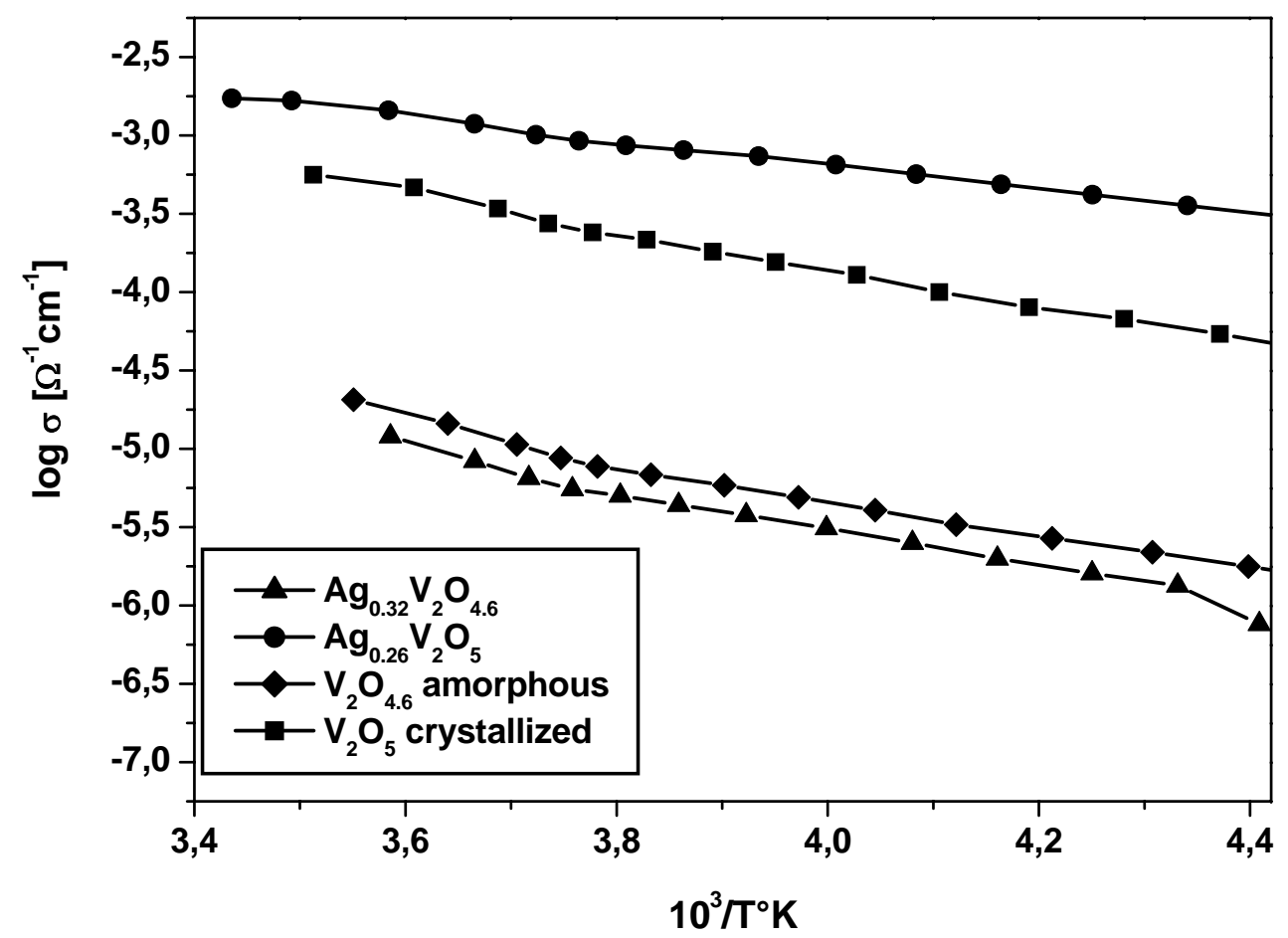




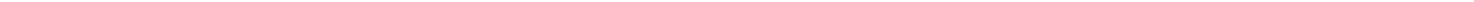

Figure4, 0 


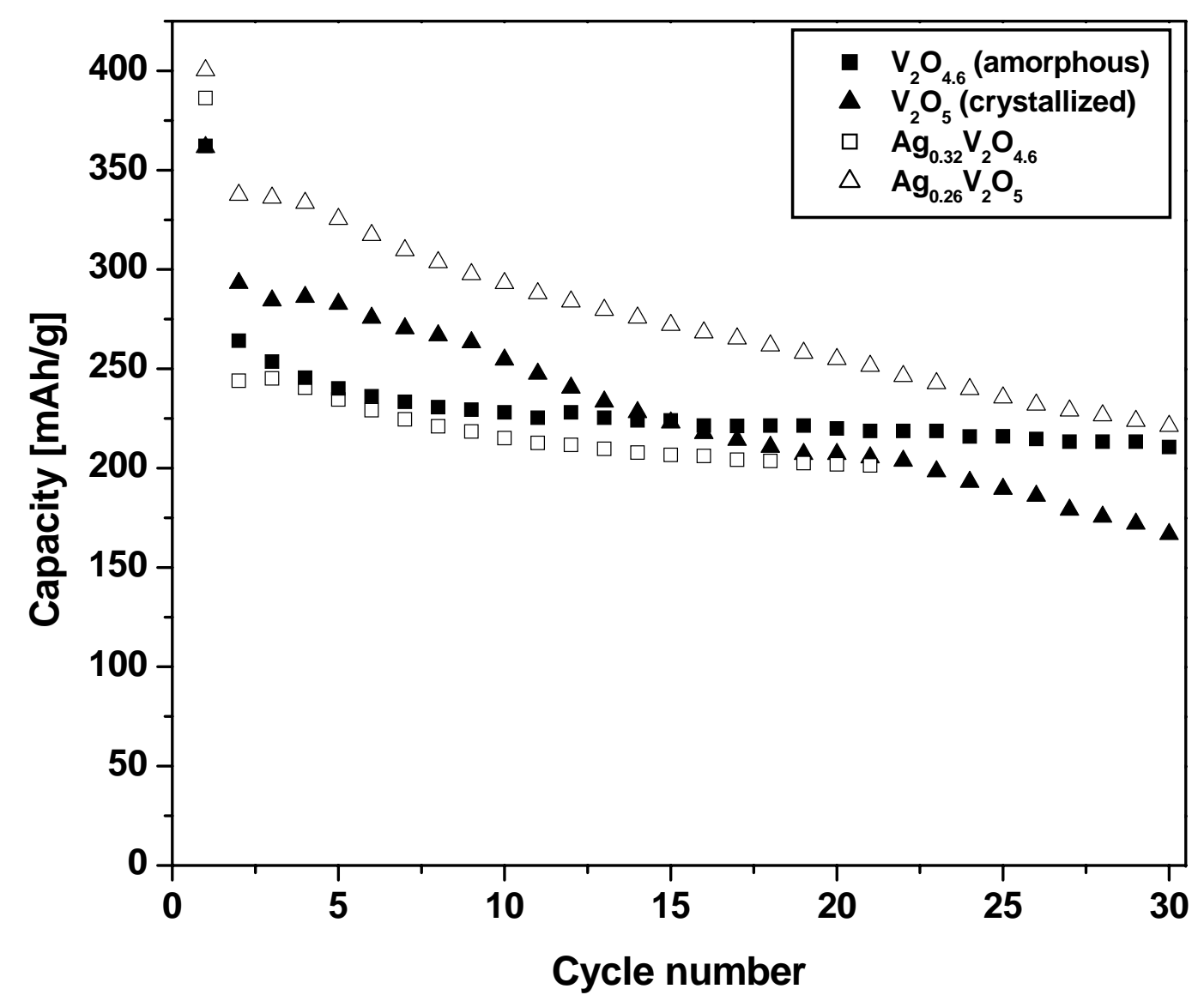




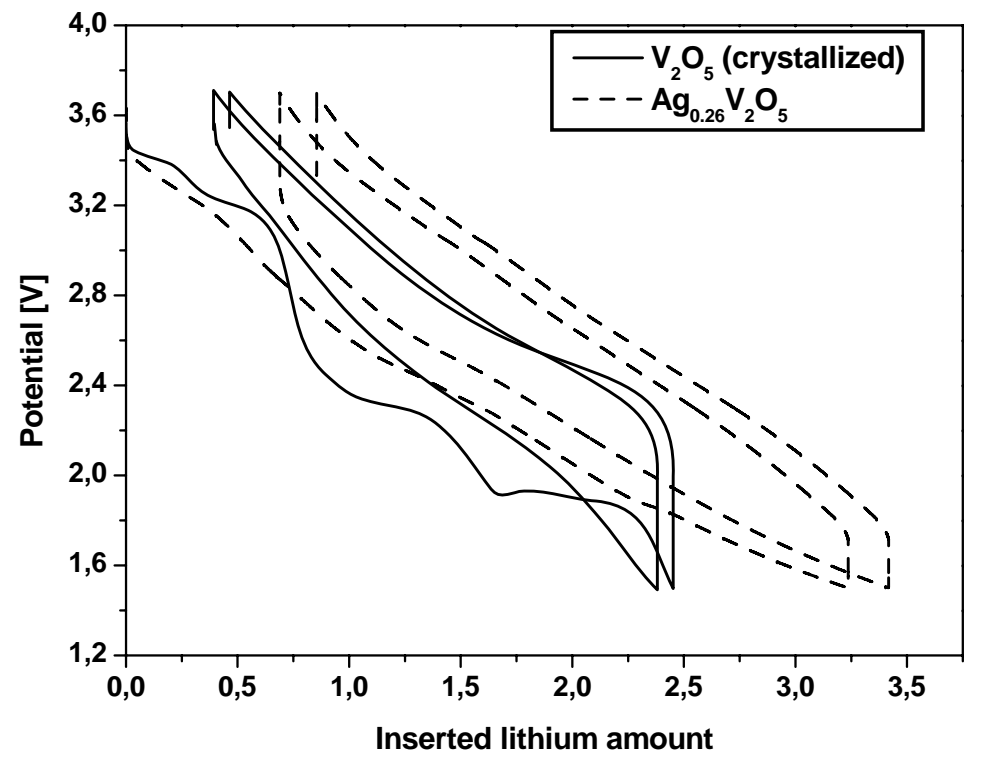



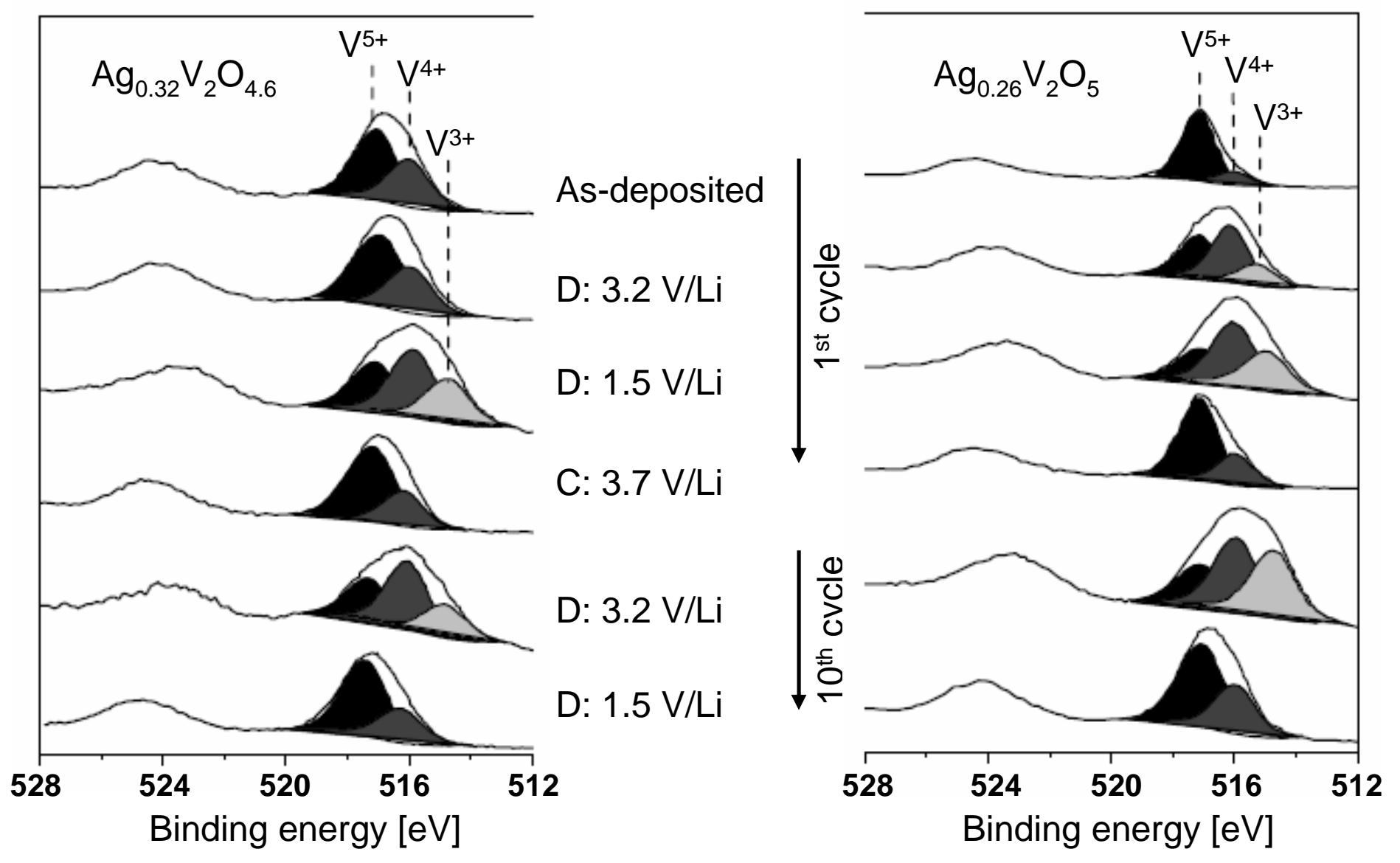


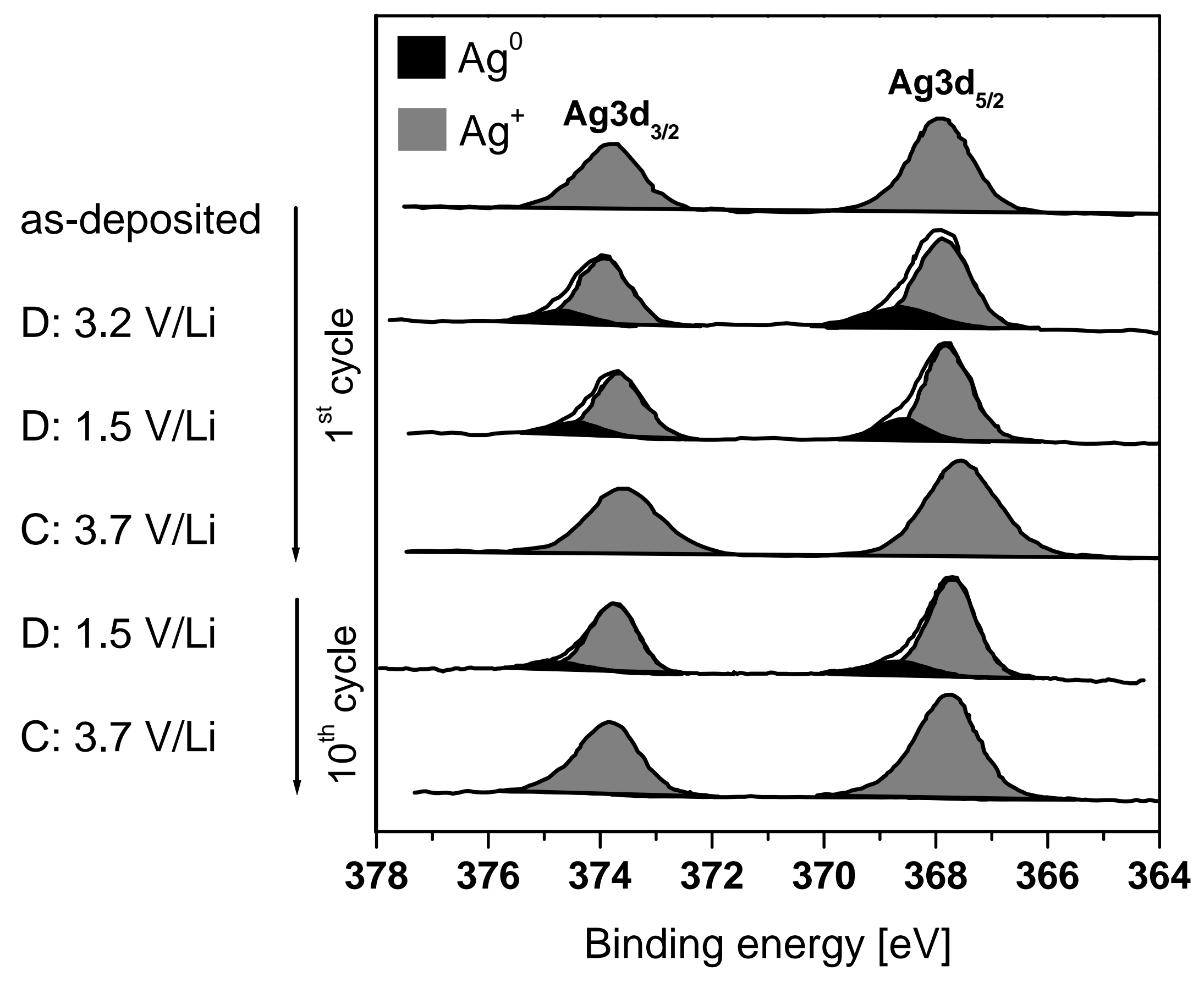

